\title{
Probabilistic Skill of Subseasonal Precipitation Forecasts for the East Africa-West Asia Sector during September-May
}

\author{
N. VIGAUD \\ International Research Institute for Climate and Society, Earth Institute, Columbia University, Palisades, New York \\ M. K. TIPPETT \\ Department of Applied Physics and Applied Mathematics, Columbia University, New York, New York
}

A. W. ROBERTSON

International Research Institute for Climate and Society, Earth Institute, Columbia University, Palisades, New York

(Manuscript received 24 April 2018, in final form 25 September 2018)

\begin{abstract}
The skill of submonthly forecasts of rainfall over the East Africa-West Asia sector is examined for starts during the extended boreal winter season (September-April) using three ensemble prediction systems (EPSs) from the Subseasonal-to-Seasonal (S2S) project. Forecasts of tercile category probabilities over the common period 1999-2010 are constructed using extended logistic regression (ELR), and a multimodel forecast is formed by averaging individual model probabilities. The calibration of each model separately produces reliable probabilistic weekly forecasts, but these lack sharpness beyond a week lead time. Multimodel ensembling generally improves skill by removing negative skill scores present in individual models. In addition, the multimodel ensemble week-3-4 forecasts have a higher ranked probability skill score and reliability compared to week-3 or week-4 forecasts for starts in February-April, while skill gain is less pronounced for other seasons. During the 1999-2010 period, skill over continental subregions is the highest for starts in February-April and for starts during El Niño conditions and MJO phase 7, which coincides with enhanced forecast probabilities of abovenormal rainfall. Overall, these results indicate notable opportunities for the application of skillful subseasonal predictions over the East Africa-West Asia sector during the extended boreal winter season.
\end{abstract}

\section{Introduction}

The climate from East Africa to West Asia is highly heterogeneous because of contrasting topography and regional atmospheric processes across the three subcontinents (i.e., East Africa, the Arabian Peninsula, and West Asia); however it is tightly associated with the latitudinal migration of the intertropical convergence zone (ITCZ), which modulates the north (southeast) trades during the southern (northern) summer. This heterogeneity and north-south ITCZ migration is clear in the climatological seasonal rainfall from September to April over the semiarid to arid regions within the East Africa-West Asia (EA-WA) sector Fig. 1. Over East Africa, the ITCZ migration results in two rainy seasons: the "short" rains from

\footnotetext{
Corresponding author: N. Vigaud, nicolas.vigaud@gmail.com
}

October to December (OND) and the "long" rains from March to May (MAM). The climate of the semiarid Arabian Peninsula is also marked by a strong seasonality with a 6-month wet period (NovemberApril) during which most of the rainfall results from tropical-temperate interactions between surface troughs over Sudan and the Red Sea, and upper-level Mediterranean cyclones, as well as Rossby waves associated with the subtropical jet (Abdullah and Al-Mazroui 1998; de Vries et al. 2013). Some areas in south Oman are impacted by the southwest Indian monsoon and have their rainy season during JuneSeptember (Charabi and Abdul-Wahab 2009). The main rainy season also occurs during boreal winter in November-April over West Asian regions from the Middle East to Iran, where eastward propagating synoptic storms are the main source of precipitation (Barlow et al. 2005; Rubin et al. 2007). 


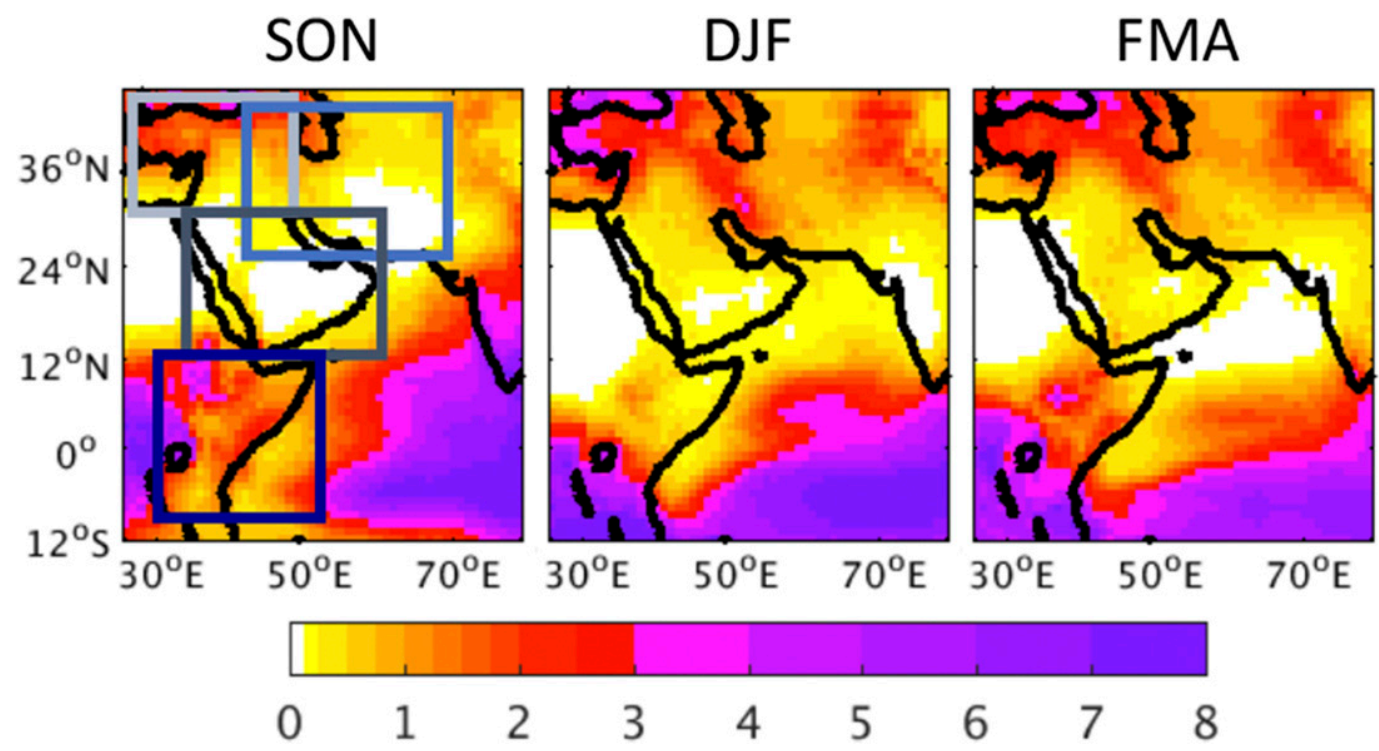

FIG. 1. Mean GPCP rainfall during (left) SON, (center) DJF, and (right) FMA (mm day ${ }^{-1}$ ) over the 1999-2010 period of study. The blue rectangles in the left panel indicate the Arabian Peninsula, East Africa, the Middle East, and Persian regions domains used in the following.

Intraseasonal rainfall variability has devastating impacts in these semiarid-to-arid regions already under seasonal hydrological stress, and forecast information beyond the seasonal cycle could be valuable for disaster risk and preparedness actions (World Meteorological Organization 2013). Despite the relative scarcity of rainfall in the region, flooding events in the Middle East from east Egypt to parts of Saudi Arabia, such as the 2009 Jeddah flood, cause significant property damage and loss of life. These events are often related to tropical-temperate interactions and modulations of stratospheric potential vorticity intrusions associated with Rossby wave breaking alongside incursions of tropical moisture into the subtropics from atmospheric rivers (de Vries et al. 2018) that could thus be useful predictors of heavy rainfall events in submonthly forecasts. More generally, a better understanding of climate phenomena on subseasonal time scales such as the Madden-Julian oscillation (MJO; Zhang 2013) together with modeling advances (Vitart 2014) has led to increased interest (Zhu et al. 2014; Vigaud et al. 2017a; Moron et al. 2018) in predictions between mediumrange weather (up to 2 weeks) and seasonal climate (from 3 to 6 months). Sources of predictability at these time scales include the inertia of sea surface temperature (SST) anomalies and the MJO (Waliser et al. 2003; Waliser 2011; Mani et al. 2014), stratospheric processes (Baldwin and Dunkerton 2001; Scaife and Knight 2008), and memory in soil moisture (Koster et al. 2010), snow cover (Lin and $\mathrm{Wu}$ 2011), and sea ice (Holland et al. 2011). From East Africa to West Asia, the influences of
El Niño-Southern Oscillation (ENSO) and the MJO are significant to varying degrees, depending on the location and season, thus raising the possibility that these sources of predictability might result in relatively skillful S2S forecasts for the region. From this perspective, the skill of submonthly precipitation forecasts with weekly (from week 1 through week 4) and biweekly (weeks 3 and 4 ) targets [i.e., the periods from $(d+1, d+7)$ to $(d+15, d+28)$ for a forecast issued on day $d$ ] for starts, or initialization times, in SeptemberApril (i.e., September-May targets), is examined over East Africa, the Arabian Peninsula, the Middle East, and Persian regions.

Seasonal variations in rainfall over the EA-WA sector have been examined in earlier studies, which identified associations with Indian Ocean (IO) SSTs and ENSO (Beltrando 1990; Beltrando and Camberlin 1993; Mason 1995; Walker 1990; Goddard and Graham 1999; Indeje et al. 2000; Behera et al. 2005; Feudale and Kucharski 2013; Nicholson 2015; Kang et al. 2015). ENSO's influence on East African short rains appears to be modulated through IO SSTs (Goddard and Graham 1999), and seasonal forecasts of the short rains are more skillful than those of the long rains (Ogutu et al. 2017). Less is known regarding ENSO teleconnections during the long rains (Ogallo 1988; Ogallo et al. 1988; Hastenrath et al. 1993; Phillips and McIntyre 2000), although relationships have been identified between the recent drying during MAM and an increased zonal SST gradient between the west and central Pacific (Lyon and DeWitt 2012; Liebmann et al. 2014; 
Vigaud et al. 2016). Convection over the IO is modulated by ENSO, in turn generating an eastwardpropagating barotropic Rossby wave response over the Northern Hemisphere (Trenberth et al. 1998; Shaman and Tziperman 2005) including Asia (Barlow et al. 2002). While ENSO relationships to the Indian summer monsoon have been documented in numerous studies, those to West Asian winter precipitation have been less studied. Since the 1980s, however, the monsoon has been significantly stronger during El Niño in association with stronger Pacific SST anomalies (Kumar et al. 2007; Yadav et al. 2010) while also impacting winter rainfall in the Middle East (Kang et al. 2015).

At intraseasonal time scales, the MJO has a strong influence on precipitation in the EA-WA sector, where a similar mechanism to the ENSO one consists of simple Gill-Matsuno dynamics (Matsuno 1966; Gill 1980) in which large-scale equatorial waves interact with local conditions (Barlow et al. 2005; Lau et al. 2012). During East African long rains, the MJO contributes substantially to intraseasonal rainfall variability, including extreme events (Pohl and Camberlin 2006b). Periods of strong MJO influence are generally characterized by upper-level temperature anomalies in response to Kelvin wave dynamics with a precursive signal in the upper-troposphere westerlies 2 weeks in advance. However, ENSO significantly modulates MJO influence locally (Mutai and Ward 2000; Kijazi and Reason 2005; Pohl and Camberlin 2006a,b). Intraseasonal convection variability in the $\mathrm{IO}$ is translated into a stationary wave over Asia (Barlow et al. 2005; Hoell et al. 2013), where MJO-induced modulations of convection have a strong influence on continental precipitation (Barlow et al. 2002, 2005; Jones et al. 2004; Nazemosadat and Ghaedamini 2010). In particular, some regional flooding events are related to tropical moisture plumes favored during MJO phases 5-8 (Rubin et al. 2007; Lau et al. 2012). Consistent year-to-year MJO influence could translate into the potential for predictability beyond 2 weeks, but to date has not been demonstrated in terms of submonthly forecast skill (Barlow et al. 2005; Lau et al. 2012).

The need for the calibration of model probabilities to account for their deficiencies and to produce reliable forecasts (Goddard et al. 2001; Wilks 2002; Tippett et al. 2007) has been demonstrated for probabilistic seasonal climate and medium-range forecasting, alongside the value of model output statistics (MOS) to improve weather probabilistic forecasts (Hamill et al. 2004). However, analysis at subseasonal time scales is limited (DelSole et al. 2017; Vigaud et al. 2017a,b). Particular challenges in analyzing subseasonal skill and predictability are the shorter hindcasts (reforecasts) with fewer ensemble members as compared to seasonal predictions, as well as generally lower skill. As for seasonal (Robertson et al. 2004) and medium-range (Hamill and Whitaker 2006) forecasting, recent studies over North America and boreal summer monsoon regions (Vigaud et al. 2017a,b) suggest that skill can be enhanced by multimodel ensembling of submonthly forecasts. Nevertheless, such findings remain to be demonstrated for the EA-WA sector. In the previous studies, extended logistic regression (ELR), which includes the quantile threshold along with the ensemble mean as a predictor, is used to produce mutually consistent quantile probabilities that sum to one property (Wilks 2009; Wilks and Hamill 2007). This ELRbased approach is used in this study to produce weekly and week-3-4 multimodel ensemble (MME) precipitation tercile probabilities forecasts from three individual ensemble prediction system (EPS) reforecasts over the EA-WA sector, and their skill is diagnosed over four subregions: East Africa, the Arabian Peninsula, the Middle East, and Persian regions. In this effort, ELR is applied at each grid point of the EA-WA sector to the individual model forecasts, which are subsequently averaged together with equal weighting. The paper is outlined as follows. The data and methods are presented in section 2 with diagnostics of the ELR model setup when applied to weekly varying precipitation tercile averages. The skill of starts during SeptemberNovember (SON), December-February (DJF), and February-April (FMA) is examined in section 3, first at weekly resolution. Skill in predicting week-3-4 averages is then discussed alongside ENSO and MJO relationships. Conclusions are drawn in section 4 .

\section{Data and methods}

\section{a. Observation and model datasets}

Daily precipitation fields from the European Centre for Medium-Range Weather Forecasts (ECMWF), the National Centers for Environmental Prediction (NCEP) CFSv2, and the China Meteorological Administration (CMA) week-1-4 reforecasts [i.e., the periods from $(d+1$, $d+7)$ to $(d+22, d+28)$ for a forecast issued on day $d]$ were obtained from the Subseasonal-to-Seasonal (S2S) database (Vitart et al. 2017) through the IRI Data Library (IRIDL) portal. These EPSs have different native resolutions (from $125 \mathrm{~km}$ at the equator with 40 vertical levels for CMA to $16 / 32 \mathrm{~km}$ and 91 vertical levels for ECMWF) and are archived on a common $1.5^{\circ}$ grid. The ensemble members (51 for ECMWF, 4 for NCEP and CMA) and reforecasts length (between 44- and 60-day leads from the NCEP CFSv2 to CMA) depend on the modeling center, as indicated in Table 1; see Vitart et al. (2017) for more details. NCEP and CMA reforecasts are 
TABLE 1. ECMWF, NCEP, and CMA forecast attributes as archived in the S2S database at ECMWF. Ensemble size corresponds to the number of forecast members produced at the respective operational centers and RFC size to the number of members archived in the corresponding reforecast database.

\begin{tabular}{lccc}
\hline \hline \multicolumn{1}{c}{ Attributes } & ECMWF & NCEP & CMA \\
\hline Time range (days) & $0-46$ & $0-44$ & $0-60$ \\
Resolution & Tco639/319 L91 & T126L64 & T106L40 \\
Ensemble size & 51 & 16 & 4 \\
Frequency & Twice per week & Daily & Daily \\
Reforecasts (RFC) & On the fly & Fixed & Fixed \\
RFC length & Past 20 years & 1999-2010 & 1994-2014 \\
RFC frequency & Twice per week & Daily & Daily \\
RFC size & 11 & 4 & 4 \\
\hline
\end{tabular}

generated four times daily from fixed model versions, contrasting with those from ECMWF, which are generated on the fly every Monday and Thursday (11 members). We consider here ECMWF reforecasts that were generated for Thursday starts in 2016, and matching NCEP and CMA four-member daily reforecasts during the common period 1999-2010, and that is the period used in our analysis. For each model, there are 132 forecasts for the DJF season and 144 for SON/FMA (12 starts over 11 and 12 years, respectively) used in this study. To produce comparable sets of forecasts, S2S data are spatially interpolated onto the Global Precipitation Climatology Project (GPCP) $1^{\circ}$ horizontal grid before the ELR forecast probabilities obtained from the three individual models are averaged to form MME tercile precipitation forecasts. The skill of starts in SON, DJF, and FMA (i.e., OND, JFM, and MAM targets at week-3-4 leads) is then assessed separately over the Arabian Peninsula $\left(12^{\circ}-30^{\circ} \mathrm{N}, 35^{\circ}-60^{\circ} \mathrm{E}\right)$, East Africa $\left(10^{\circ} \mathrm{S}-12^{\circ} \mathrm{N}, 30^{\circ}-52^{\circ} \mathrm{E}\right)$, the Middle East $\left(30^{\circ}-43^{\circ} \mathrm{N}\right.$, $\left.24^{\circ}-50^{\circ} \mathrm{E}\right)$, and Persian regions $\left(24^{\circ}-42^{\circ} \mathrm{N}^{\circ}, 41^{\circ}-70^{\circ} \mathrm{E}\right)$, as shown in Fig. 1 and also plotted in subsequent maps.

The GPCP version 1.2 (Huffman et al. 2001; Huffman and Bolvin 2012) daily rainfall estimates on a $1^{\circ}$ grid, available from 1996 to October 2015 are used as observational data for the calibration and verification of the reforecasts over the 1999-2010 period of analysis. SON, DJF, and FMA means plotted in Fig. 1 for 1999-2010 emphasize the arid-to-semiarid conditions of most regions within EA-WA sector.

Skill relationships to ENSO and the MJO are examined using the Niño-3.4 index from Barnston et al. (1997) and the MJO RMM indices from Wheeler and Hendon (2004).

\section{b. Extended logistic regression model}

Distributional regressions are well suited to probability forecasting, allowing the conditional distribution of a response variable to be derived given a set of explanatory predictors. Within this context, logistic regression can be extended to produce the probability $p$ of the verifying observation $V$ not exceeding the quantile $q$,

$$
p=\operatorname{probability}\{V \leq q\},
$$

by including an additional explanatory variable $g(q)$, which is a function of the quantile $q$ as follows:

$$
\ln \left(\frac{p}{1-p}\right)=f\left(\overline{x_{\mathrm{ens}}}\right)+g(q),
$$

where $f=b_{0}+b_{1} \overline{x_{\text {ens }}}$ and $g=b_{2} q$. When computed from Eq. (2), cumulative probabilities for smaller predictand thresholds cannot exceed those for larger thresholds across different values of the EPS ensemble mean $\overline{x_{\text {ens }}}$ (Vigaud et al. 2017a,b), thus yielding logically consistent sets of forecasts (Wilks and Hamill 2007; Wilks 2009) and allowing the flexible choice of threshold probabilities according to users' needs (Barnston and Tippett 2014). ELR is here computed for the 33rd and 67th percentiles of the precipitation distribution to produce tercile category probabilities (ELR forecasts).

The observed climatological weekly tercile categories corresponding to the 33rd and 67th percentiles from GPCP weekly cumulated precipitation estimates are defined using 3-week windows formed by the forecast target week and a week on either side. This is done separately at each grid point for each start within the September-April season (1 September-28 April Thursdays start dates) and each lead (weeks 1-4) following a leave-one-year-out approach (i.e., using the 33 and 30 weeks from the remaining 11 and 10 years for SON/FMA and DJF starts, respectively). Equivalent to a "dry mask," ELR forecasts are produced only when and where the 33rd percentile is nonzero, since the lower tercile boundary is not well defined otherwise. For week3-4 targets (from $d+15$ to $d+28$ for forecasts issued on day $d$ ) that correspond to a 2-week target at 2-week lead (Zhu et al. 2014), observed climatological biweekly tercile categories are computed on a 6-week window formed by the 2-week target and 2 weeks on either side.

For each model, grid point, calendar start date, and lead, ELR parameters are then estimated separately based on all years except the one being forecast before predicting forecasted tercile probabilities for the left-out year (validation set) that are averaged across models with equal weights to produce MMEs of the individual forecast probabilities (MME forecasts). Further details can be found in Vigaud et al. (2017a,b).

\section{c. Skill metrics}

Maps of ranked probability skill scores (RPSSs; Epstein 1969; Murphy 1969, 1971; Weigel et al. 2007) are 


\section{RPSS Week 1}
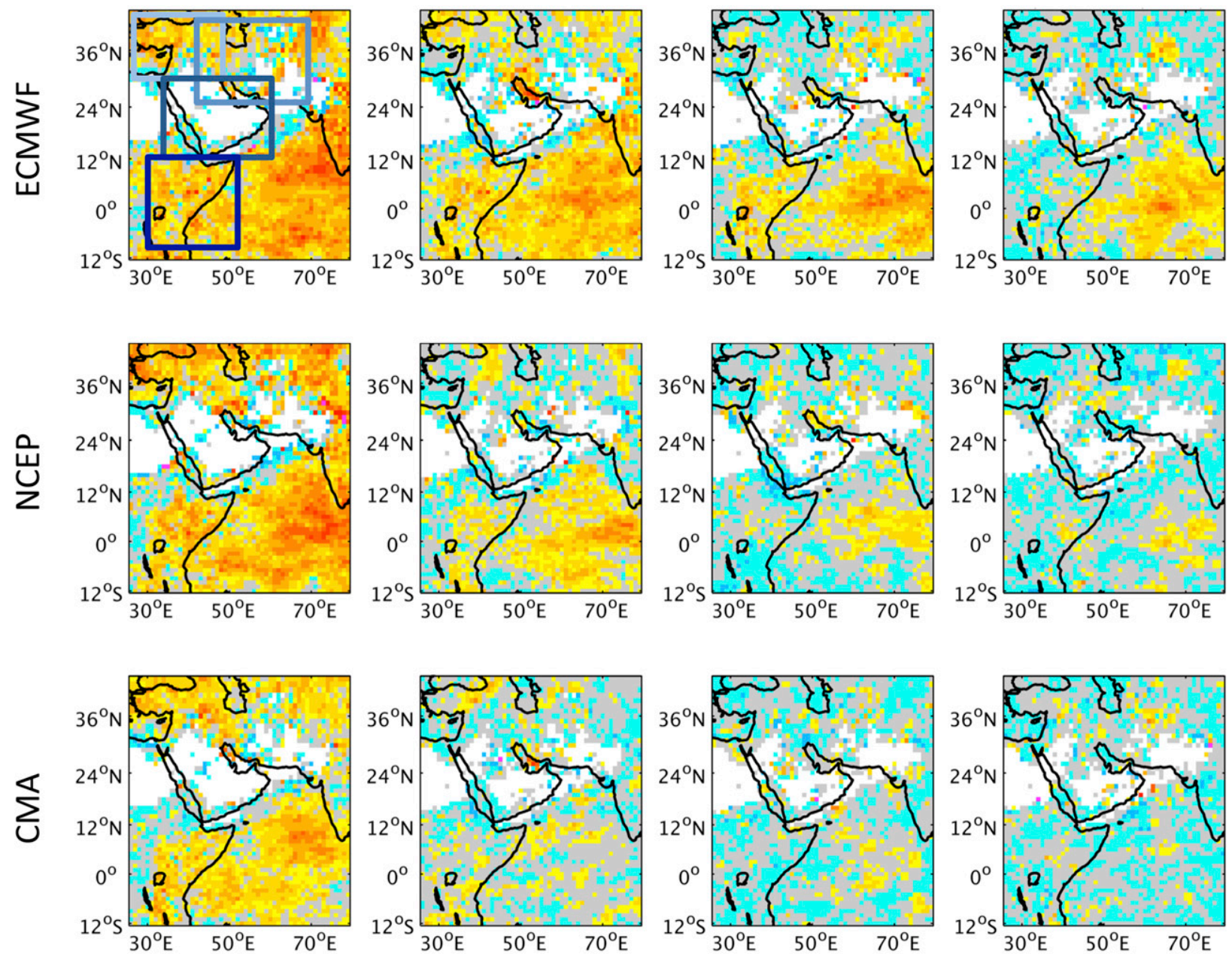

RPSS Week 2
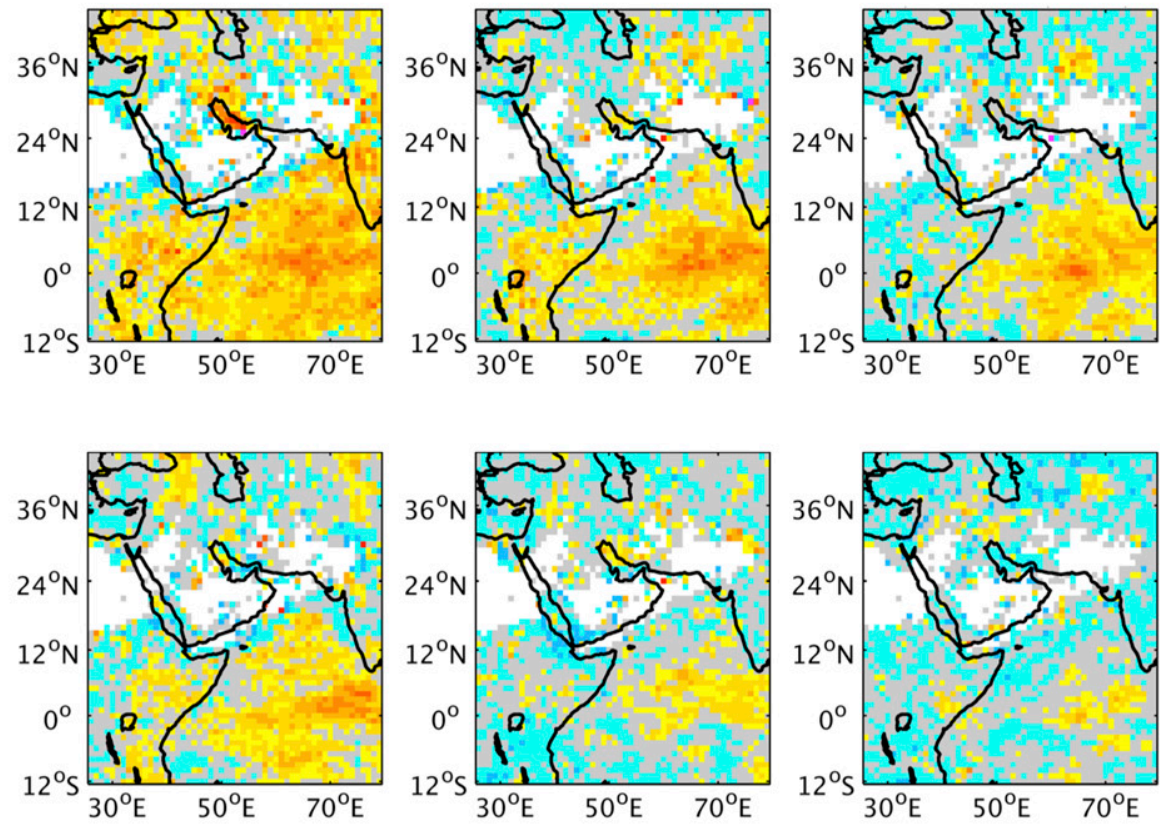
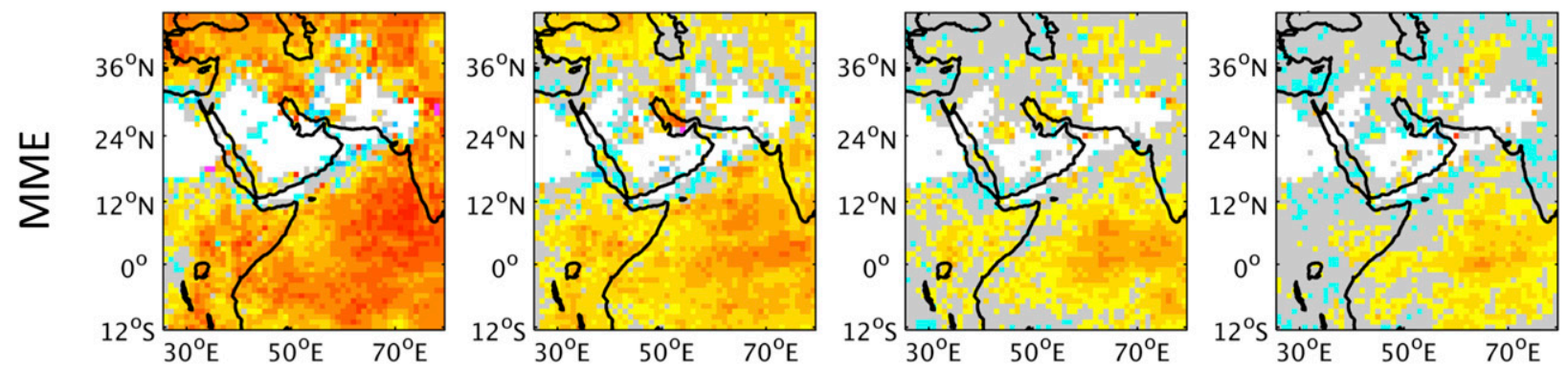

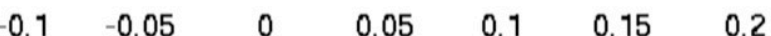

FIG. 2. RPSSs for ECMWF, NCEP, and CMA tercile precipitation forecasts as well as their MMEs for starts in SON. The different columns correspond to leads from 1 to 4 weeks. White shadings correspond to the "dry mask" for which no forecast is produced. Similarly to Fig. 1, the Arabian Peninsula, East Africa, the Middle East, and Persian regions domains used in the following are indicated by rectangles in the top-left panel. 
RPSS Week 1
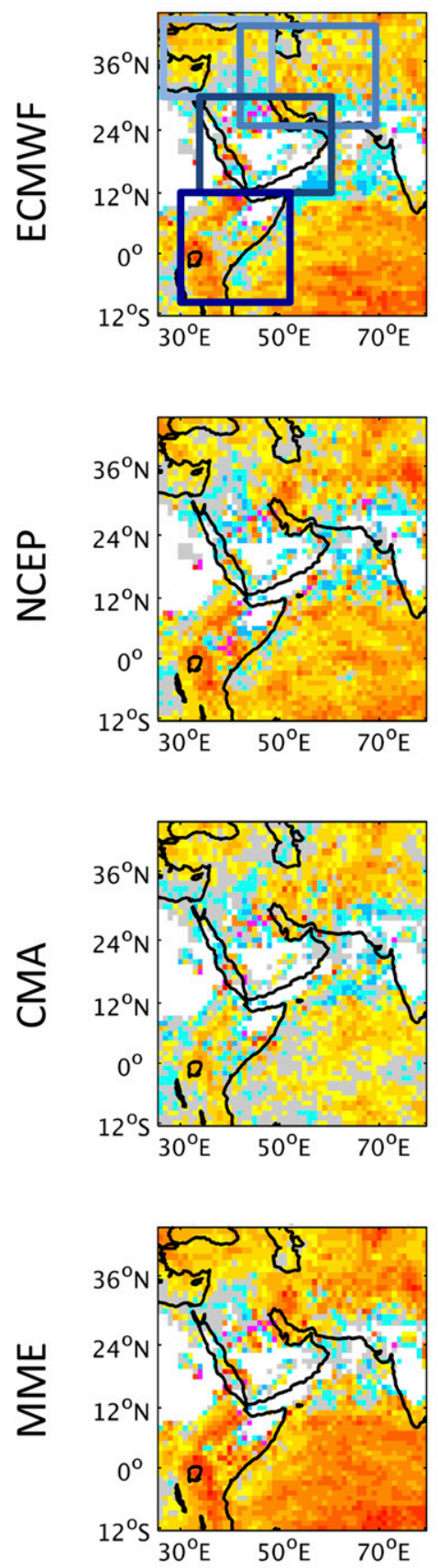

RPSS Week 2
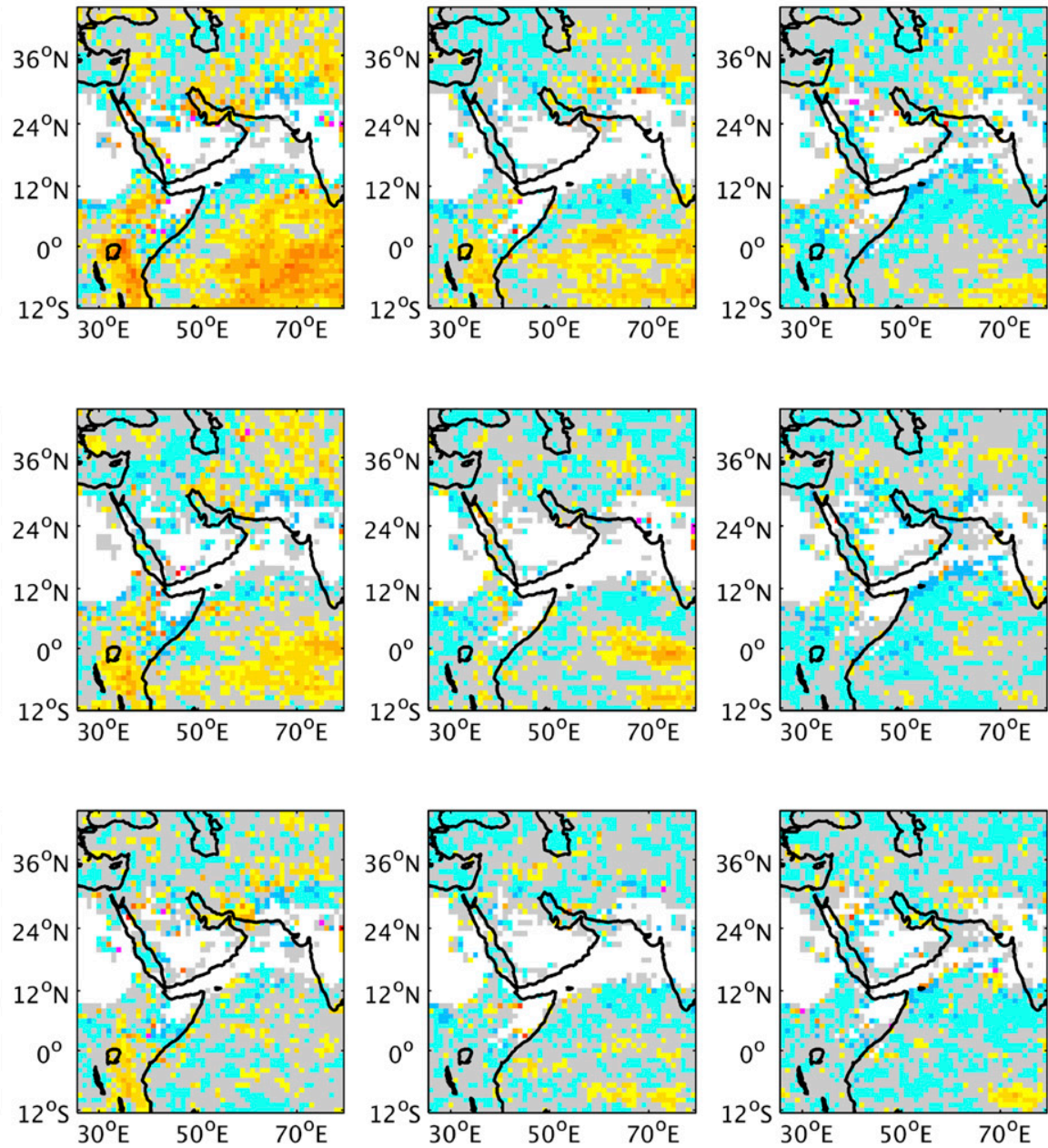

RPSS Week 3
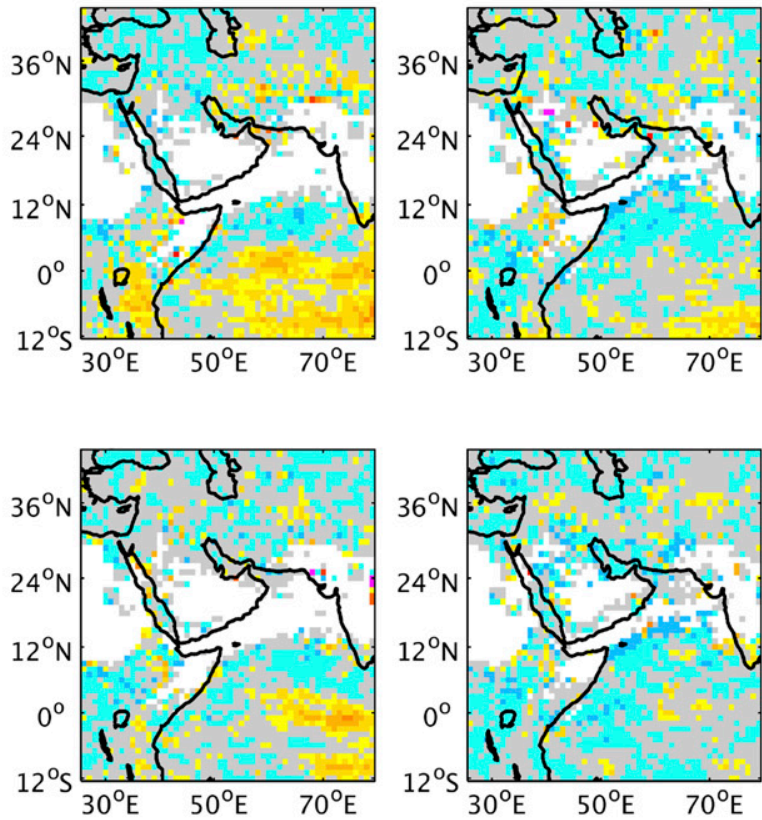

RPSS Week 4

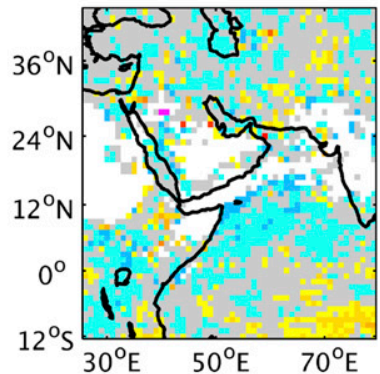

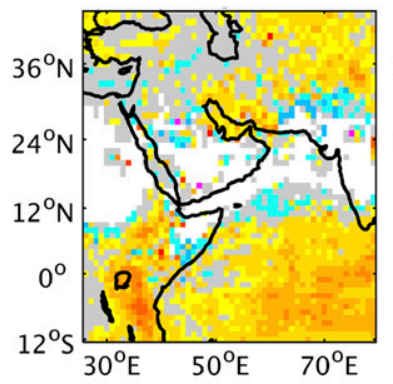
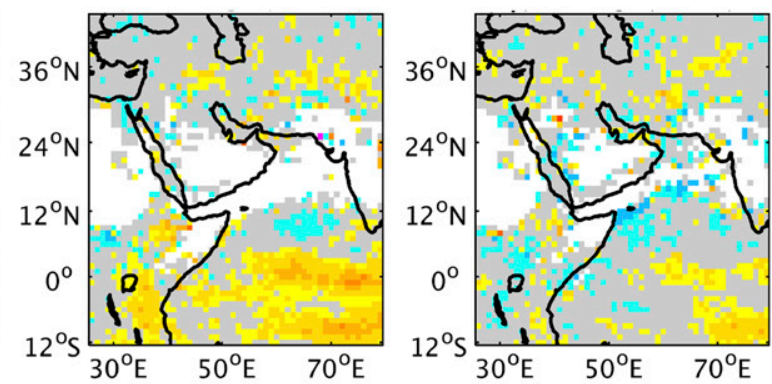

$\begin{array}{lllllll}-0.1 & -0.05 & 0 & 0.05 & 0.1 & 0.15 & 0.2\end{array}$

FIG. 3. As in Fig. 2, but for starts in DJF.

first used to quantify the extent to which the ELRcalibrated predictions are improved compared to climatological frequencies. The RPSS is a one of the most commonly used strictly proper skill scores (i.e., that cannot be increased by hedging) since it is based on both the shape and overall tendency of the forecast distribution and is thus generally preferred to other scores that are also sensitive to distance (Daan 1985; Wilks 1995; 

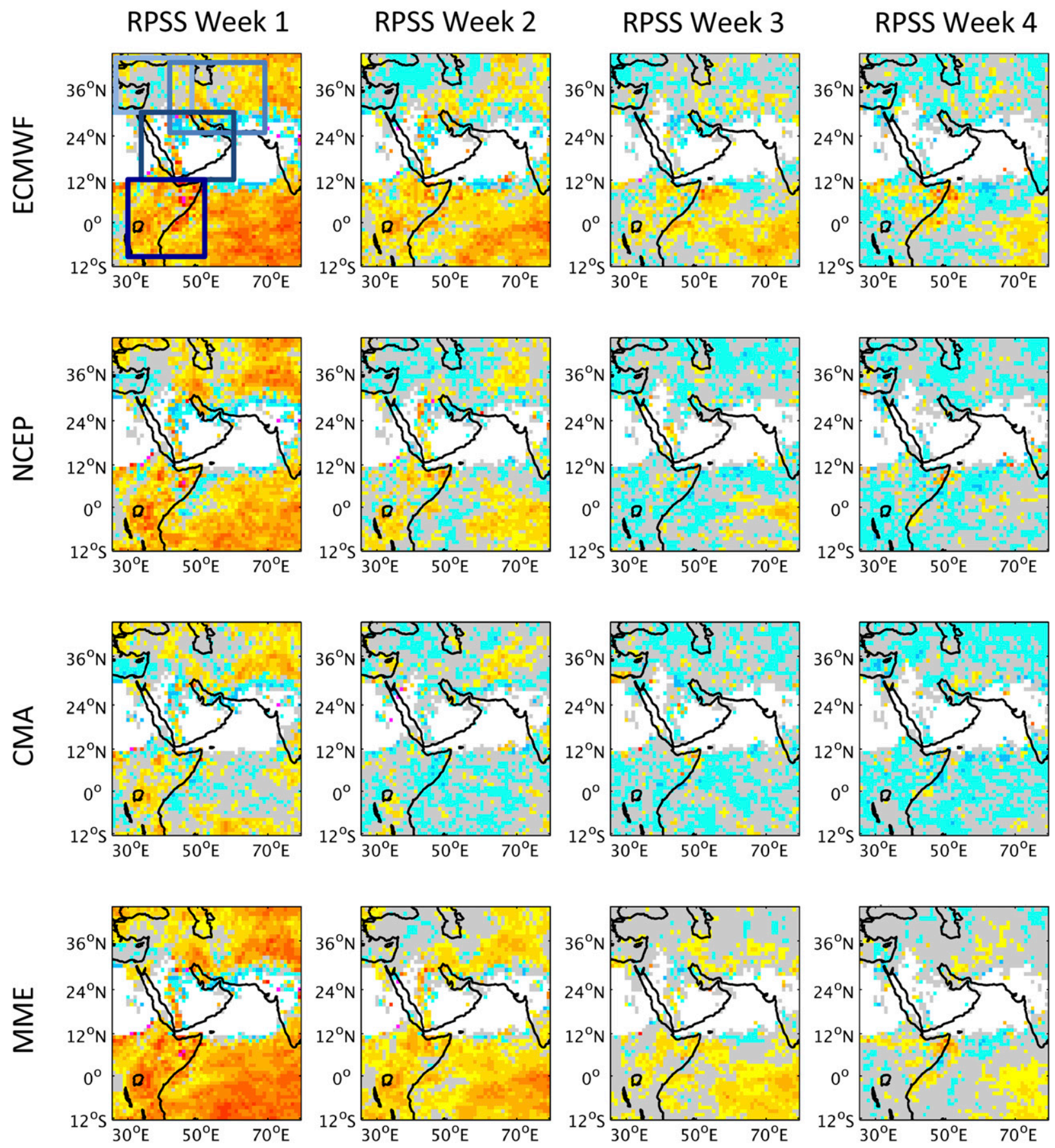

\section{$\begin{array}{lllllll}-0.1 & -0.05 & 0 & 0.05 & 0.1 & 0.15 & 0.2\end{array}$}

FIG. 4. As in Fig. 2, but for starts in FMA.

Weigel et al. 2007). RPSS values tend to be small, even for skillful forecasts. For reliable forecasts, a deterministic forecast with correlation $r$ will have an RPSS of approximately $1-\sqrt{1-r^{2}}$, which means that an RPSS value of 0.1 corresponds to a correlation of about 0.44 (Tippett et al. 2010). To complement the spatial information from RPSS maps, reliability diagrams are next computed by pooling all land points over each subregion separately to 

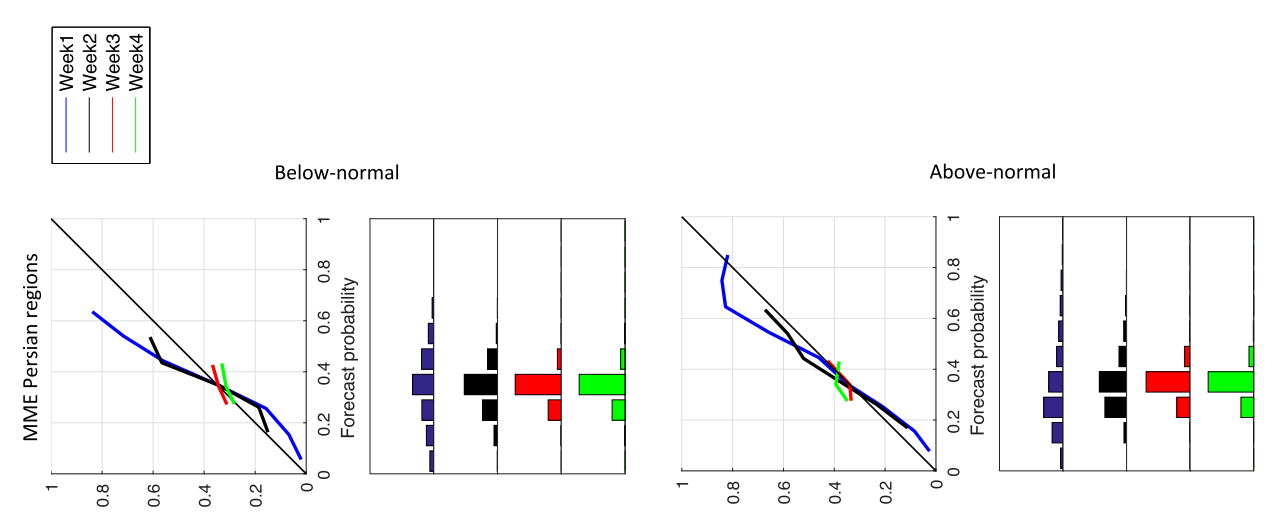

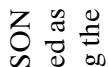

$\exists$.

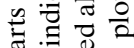

के

爱递范

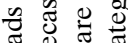

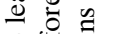

I.

光踏.

$3 \stackrel{0}{0}$

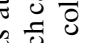
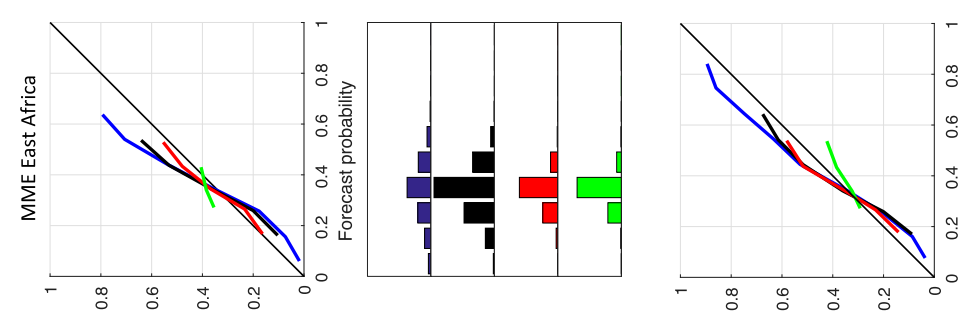

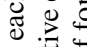
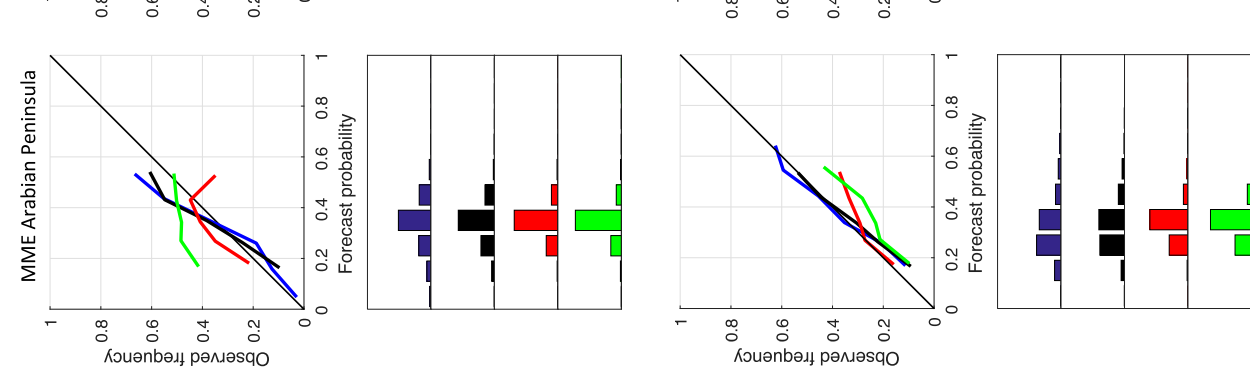

居

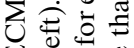

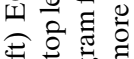

बृe

일

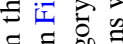

है.

ช 웡

范苛
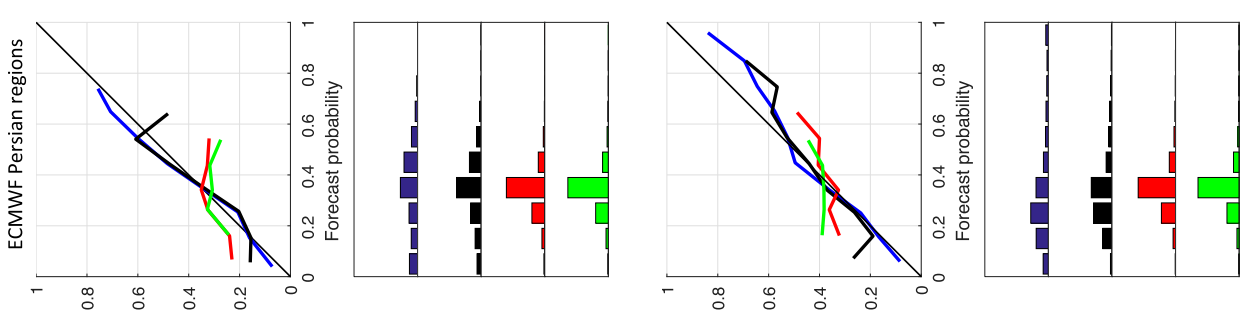

$\widetilde{0}$

즐

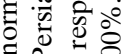

iิ ปे

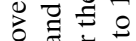

ส ฮี ஃे

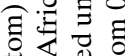

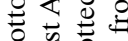

空 음
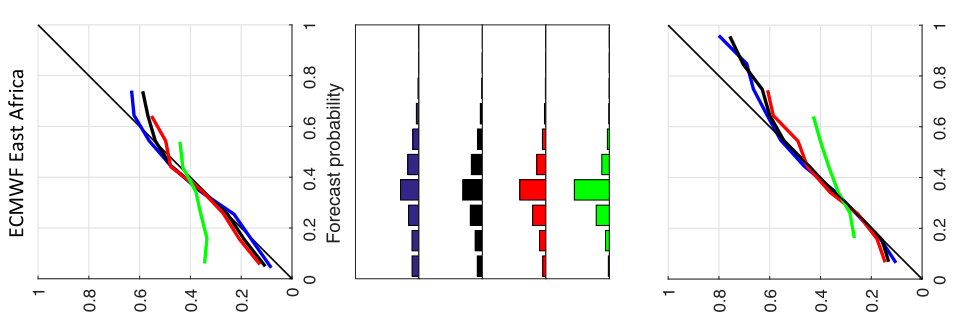

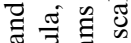

产苛

$\div$ 类

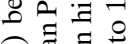

ล.. . .50

원듐응

文艺。

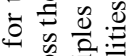
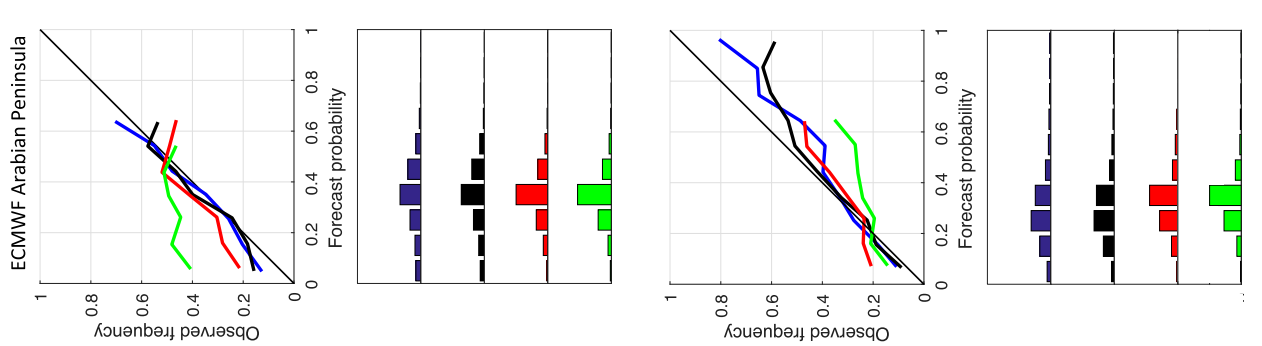

目要

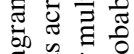

要

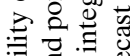

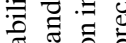

훙 훙

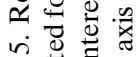

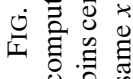




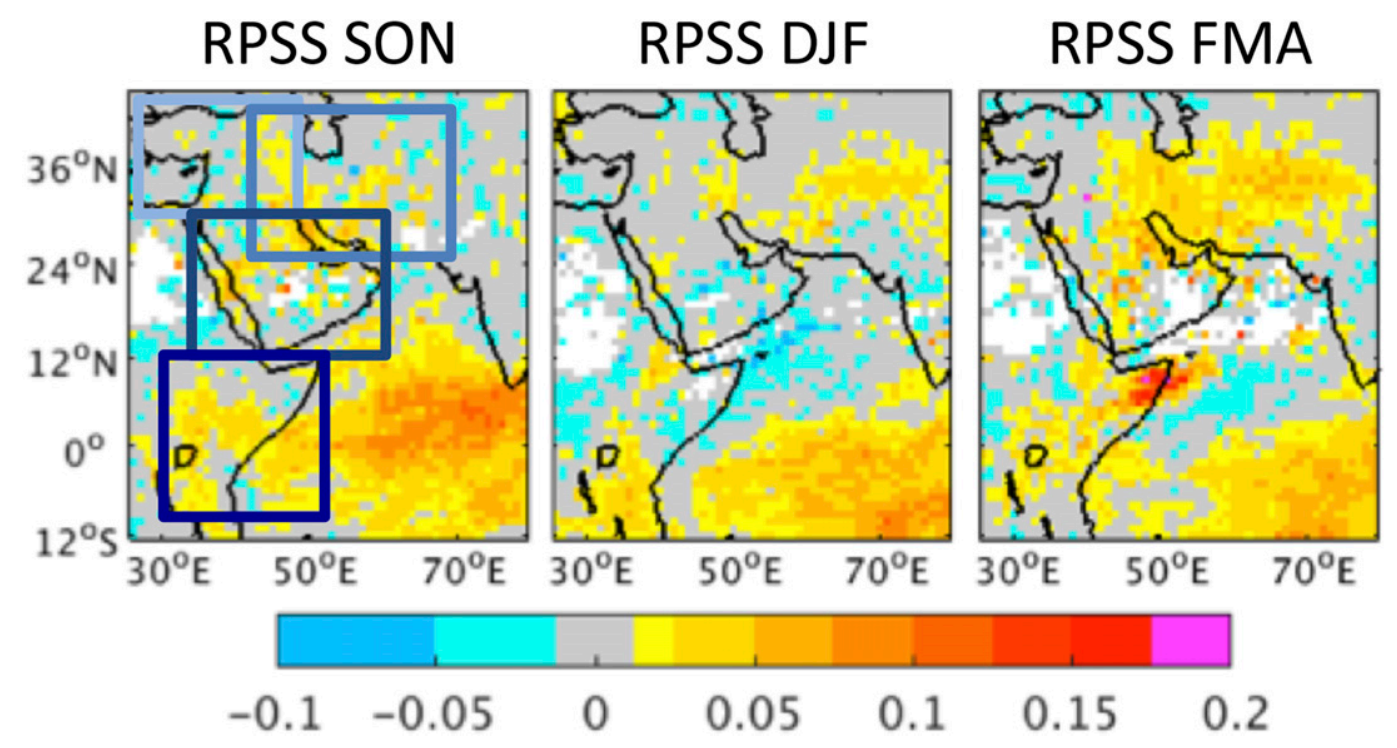

FIG. 6. RPSSs for the MMEs of ECMWF, NCEP, and CMA tercile precipitation week-3-4 forecasts for starts in (left) SON, (center) DJF, and (right) FMA.

evaluate reliability, resolution, and sharpness (Wilks 1995; Hamill 1997) of the ELR-based tercile category precipitation forecasts.

\section{d. Significance testing}

RPSS averaged for starts during specific phases of ENSO and the MJO are tested for statistical significance using Monte Carlo simulations based on many random forecasts subsets (i.e., 100000) drawn from the entire pool of forecasts with starts in SON, DJF, and FMA, from which the 90th percentile RPSS is compared to these from ENSO/MJO phase samples. Monte Carlo simulations are also used to assess the significance of the correlations of area averages of week-3-4 MME RPSSs with the observed Niño-3.4 index, MJO RMMs and their best linear combination.

\section{Results}

\section{a. Weekly averages}

Maps of RPSSs for individual models and their MMEs are shown in Fig. 2 for starts in SON. During week 1, maximum RPSS over land is found over East Africa, northern parts of the Middle East, and Persian regions, which still exhibit the largest RPSS in week 2 but with much lower magnitude. RPSS values for weeks 3 and 4 are near zero or negative everywhere, except for ECMWF in week-3 over East Africa and Persian regions. Similar results are found for DJF and FMA starts (Figs. 3 and 4), but with maximum RPSS values over the Middle East and East Africa-Persian regions, respectively, in relation to the seasonality of rainfall linked to the ITCZ latitudinal migration. Positive RPSS values for ECMWF remain until week 3 in FMA over East Africa. High RPSS values there in DJF coincide with climatologically fairly dry conditions (Fig. 1) except during El Niño events, which tend to be wet and for which forecasts are highly skillful (Fig. 11). CMA is the least skillful model and multimodel ensembling results in a slight RPSS increase in weeks 1-4 compared to the most skillful individual model (ECMWF), particularly over East Africa and Persian regions in SON and FMA, by removing the small negative RPSS values present in individual model forecasts, as evidenced over other regions of the globe (Vigaud et al. 2017a,b).

Reliability diagrams for weekly ECMWF precipitation tercile category forecasts from all weekly starts in SON and each land grid point from the subregions shown in the top-left panel of Fig. 2 (except the Middle East since there is less skill) are displayed in the top- and bottom-left panels of Fig. 5 for the below- and abovenormal categories, respectively. At week-1 lead, forecasts are characterized by reasonable reliability and resolution with blue curves close to the diagonal and distant from the climatological 0.33 horizontal line (zero resolution line; not plotted), respectively. ECMWFforecasted categories exhibit high sharpness as shown by corresponding histograms spread across all bins. Sharpness decreases with increasing lead time with maximum frequencies concentrated around climatology ( 0.33 , i.e., fourth bin), while reliability and resolution also sharply drop from weeks 1 and 2 onward as 
a) ECMWF SON

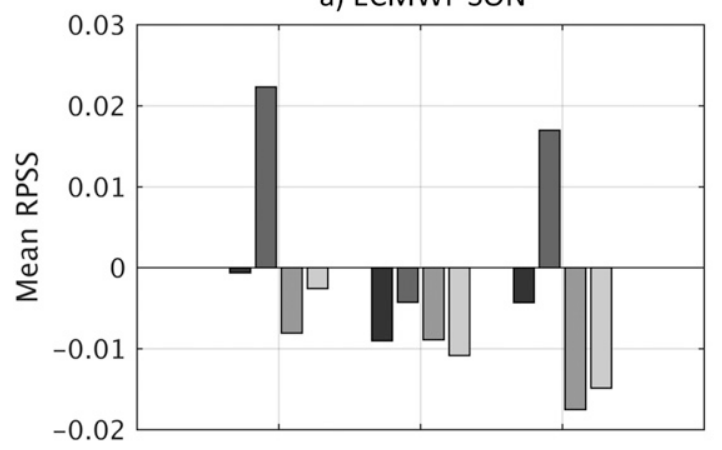

c) ECMWF DJF

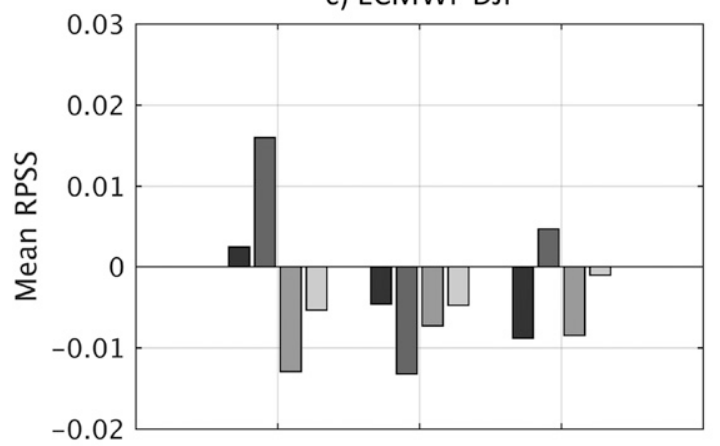

e) ECMWF FMA

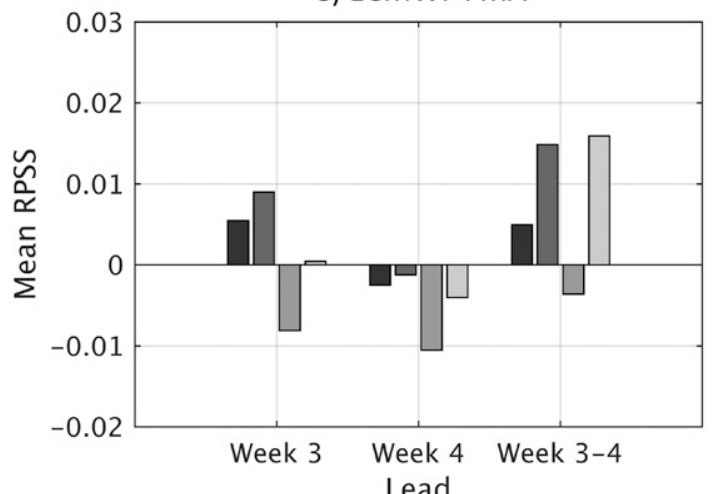

b) MME SON

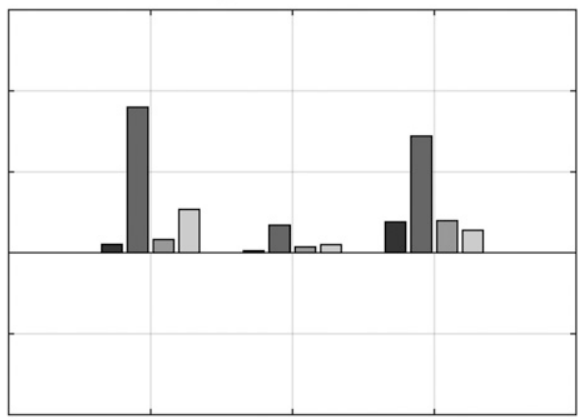

d) MME DJF

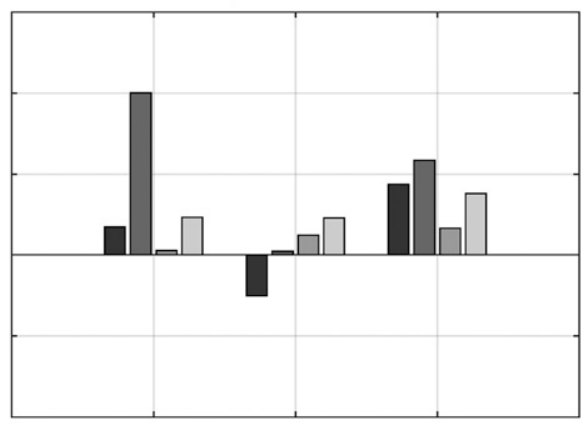

f) MME FMA

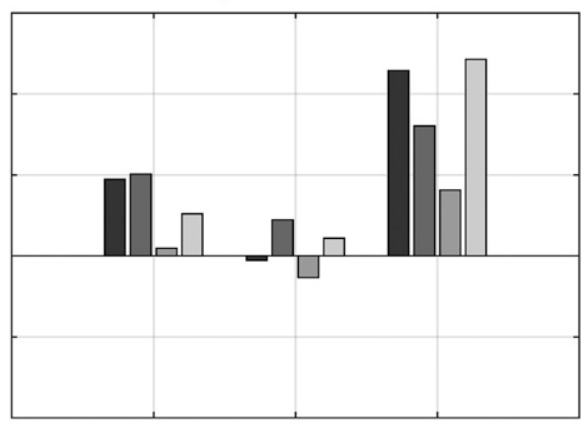

Week 3 Week 4 Week 3-4 Lead

Arabian Peninsula $\square$ East Africa $\square$ Middle East $\square$ Persian regions

FIG. 7. Mean RPSSs from (left) ECMWF and (right) MME over the Arabian Peninsula, East Africa, Middle East, and Persian regions in (top) SON, (middle) DJF, and (bottom) FMA. The Arabian Peninsula, East Africa, the Middle East, and Persian regions domains used in the following are indicated by rectangles in the left panel of Fig. 6.

indicated by decreasing slopes. Qualitatively similar results are found for the NCEP and CMA models (not shown), which are overall less skillful than ECMWF. By comparison to individual models, MME forecasts exhibit slightly greater slopes, in particular for week2 leads (Fig. 5, right), suggesting increased reliability and resolution, while sharpness becomes very low at long lead (histograms in Fig. 5, right). At week-3 and week-4 leads, MME forecasts lack reliability and display only small deviations from equal odds. Qualitatively comparable results are identified in DJF and FMA (not shown).

\section{b. Week-3-4 averages}

Maps of RPSS for week-3-4 MME outlooks and SON, DJF and FMA starts are shown in Fig. 6 and reflect more skill for week-3-4 averages than weekly forecasts at week-3 lead (Figs. 2-4, bottom). This is indicated by higher RPSS values over East Africa, the Arabian Peninsula, the Middle East, and Persian regions for 

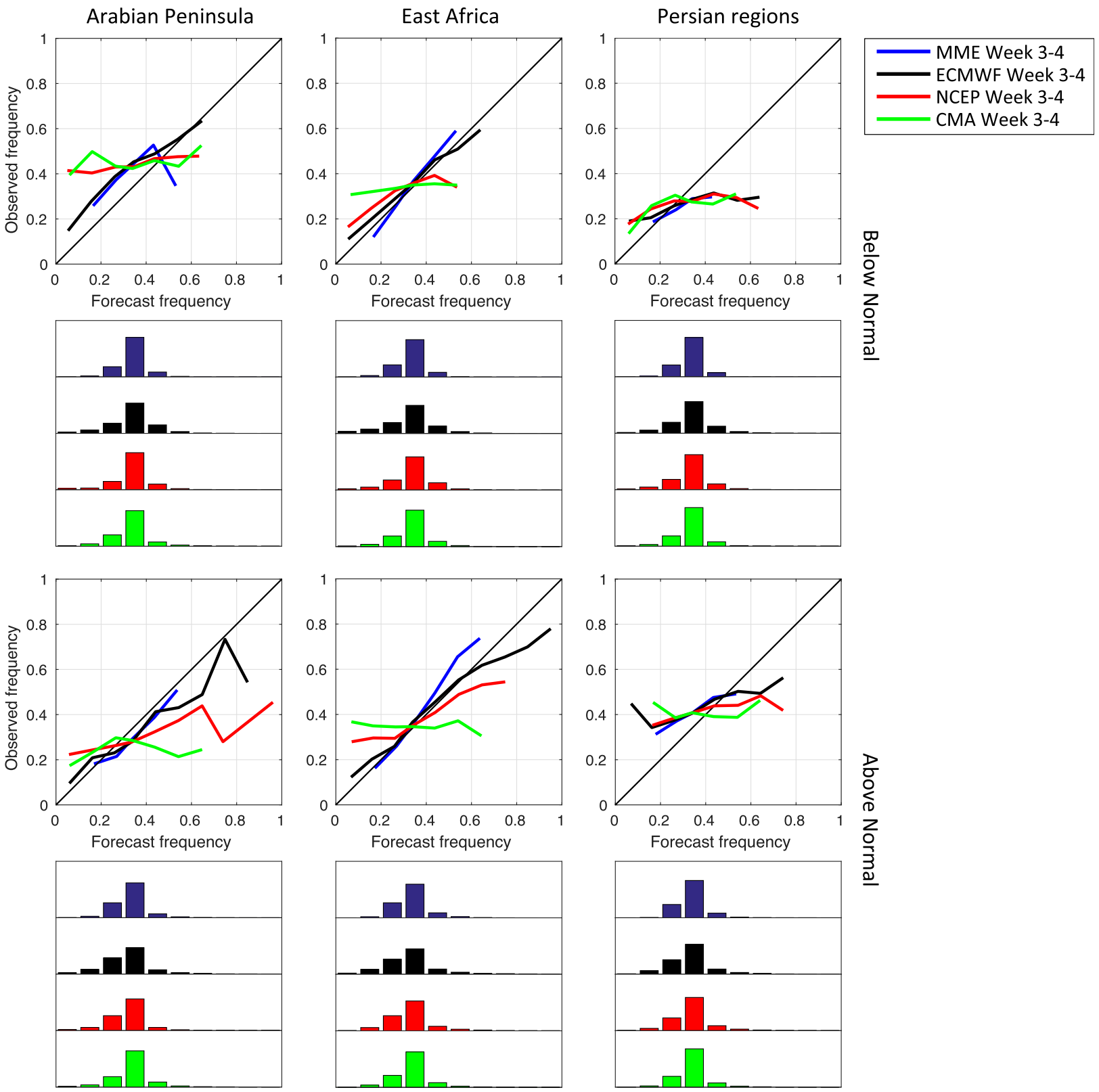

FIG. 8. Week-3-4 reliability diagrams for the (top) below- and (bottom) above-normal categories from ECWMF (black), NCEP (red), and CMA (green) forecasts with starts in SON together with their MMEs (blue) computed for land points across the (left) Arabian Peninsula, (center) East Africa, and (right) Persian regions. Frequencies with which each category is forecasted are indicated as bins centered on integer multiples of 0.10 in histograms plotted under the respective tercile category diagrams for each forecast in their respective colors. Bins are projected along the same $x$ axis (forecast probabilities from 0 to 1 ) and scaled from $0 \%$ to $100 \%$. Note that only bins with more than $0.5 \%$ of the total number of forecasts in each category are plotted.

SON and FMA starts, and the Arabian Peninsula and Persian regions in DJF, illustrating the added value of pooling week-3 and -4 leads. RPSS values averaged over the four subregions are shown in Fig. 7 for week-3, week4, and week-3-4 forecasts from ECMWF and the MME. Higher RPSS values are found for week-3-4 averages compared to week-3 and -4 forecasts over East Africa for ECMWF and over the Arabian Peninsula and the Middle East for the MME in SON, the Middle East and Persian regions in DJF, and all subregions in FMA. The average week-3-4 RPSS is greater for the MME than for ECMWF everywhere, except East Africa in SON.

Figure 8 shows reliability diagrams computed over the Arabian Peninsula, East Africa, and Persian regions for 


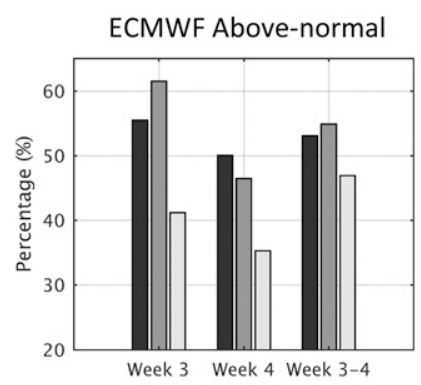

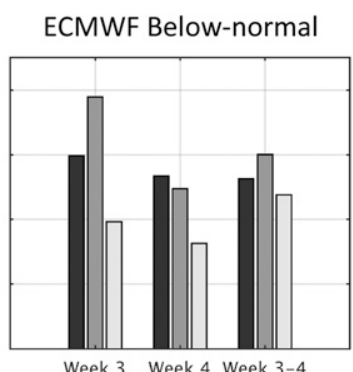

Week 3 Week 4 Week 3-4

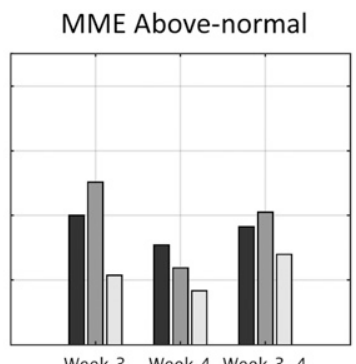

Week 3 Week 4 Week 3-4 East Africa $\square$ Persian regions

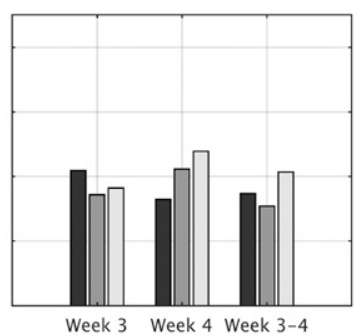
Arabian Peninsula

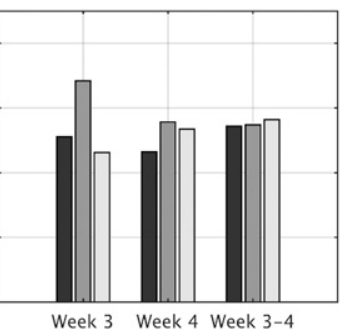

Week 3 Week 4 week 3-4

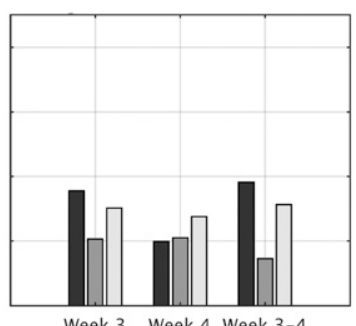

Week 3 Week 4 Week 3-4 Middle East $\square$ Persian regions

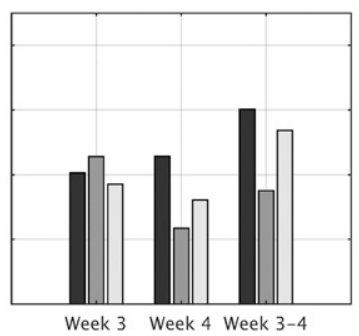

MME Below-normal
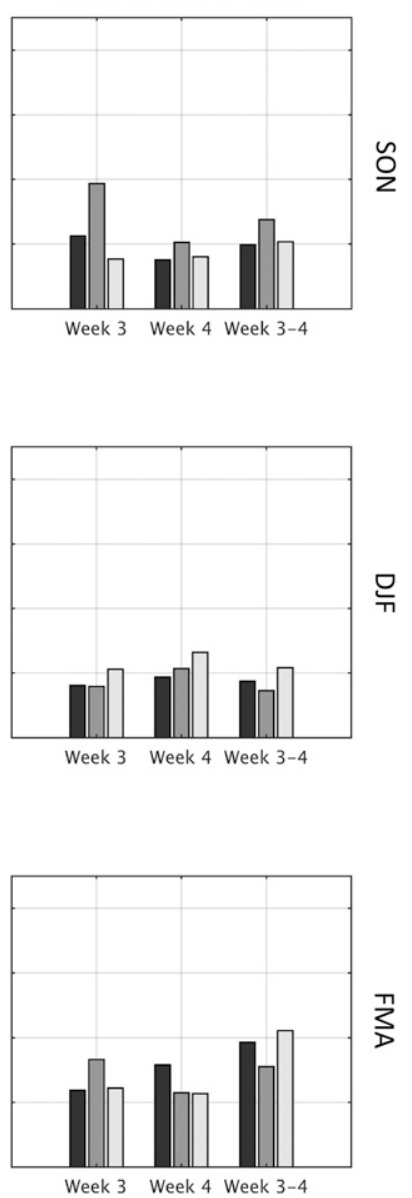

Arabian Peninsula $\square$ East Africa $\square$ Persian regions

FIG. 9. Percentages of forecasts in all bins except for the fourth bin (0.33) shown in Fig. 8 for week-3, week-4, and week-3-4 forecasts from (left) ECMWF and (right) MME with starts in (top) SON, (middle) DJF, and (bottom) FMA for the above- and below-normal categories.

the below- and above-normal categories of week-3-4 forecasts from individual models and their MMEs for SON starts. The slopes for week-3-4 averages are lower than those of week-3 forecasts but greater than for week 4 (Fig. 5), suggesting increased reliability. Multimodel ensembling leads to increased skill gain for week-3-4 forecasts compared to weekly averages; however, the skill is overall lower over Persian regions than for other subregions. As a complementary measure of sharpness, the percentage of forecast probabilities that do not fall in the climatology bin $0.3-0.4$ is next computed in Fig. 9, suggesting higher proportions of forecasts with probabilities different from climatology, and thus increased sharpness, for week-3-4 averages compared to week-3 and week-4 forecasts over Persian regions in SON and FMA, and over the Arabian Peninsula in FMA. Otherwise, the sharpness of week-3-4 averages is between those of weeks 3 and 4, except in DJF over the Middle East.

\section{c. Skill relationships to ENSO and the MJO}

Significant correlations between weekly GPCP rainfall and the Niño-3.4 index and MJO RMM indices of Wheeler and Hendon (2004) in Fig. 10 suggest that forecasts and forecast skill might be related to both large-scale signals. From this perspective, the top panels in Fig. 11 show week-3-4 MME RPSS values averaged over land grid points of the four subregions for starts during distinct ENSO conditions (neutral when the absolute value of Niño-3.4 is smaller than 0.5; El Niño and La Niña for Niño-3.4 greater and lower than 0.5, respectively) and MJO phases to get further insights into how skill varies with these tropical forcings. The Indian Ocean dipole (IOD; Saji et al. 1999) is also known to 

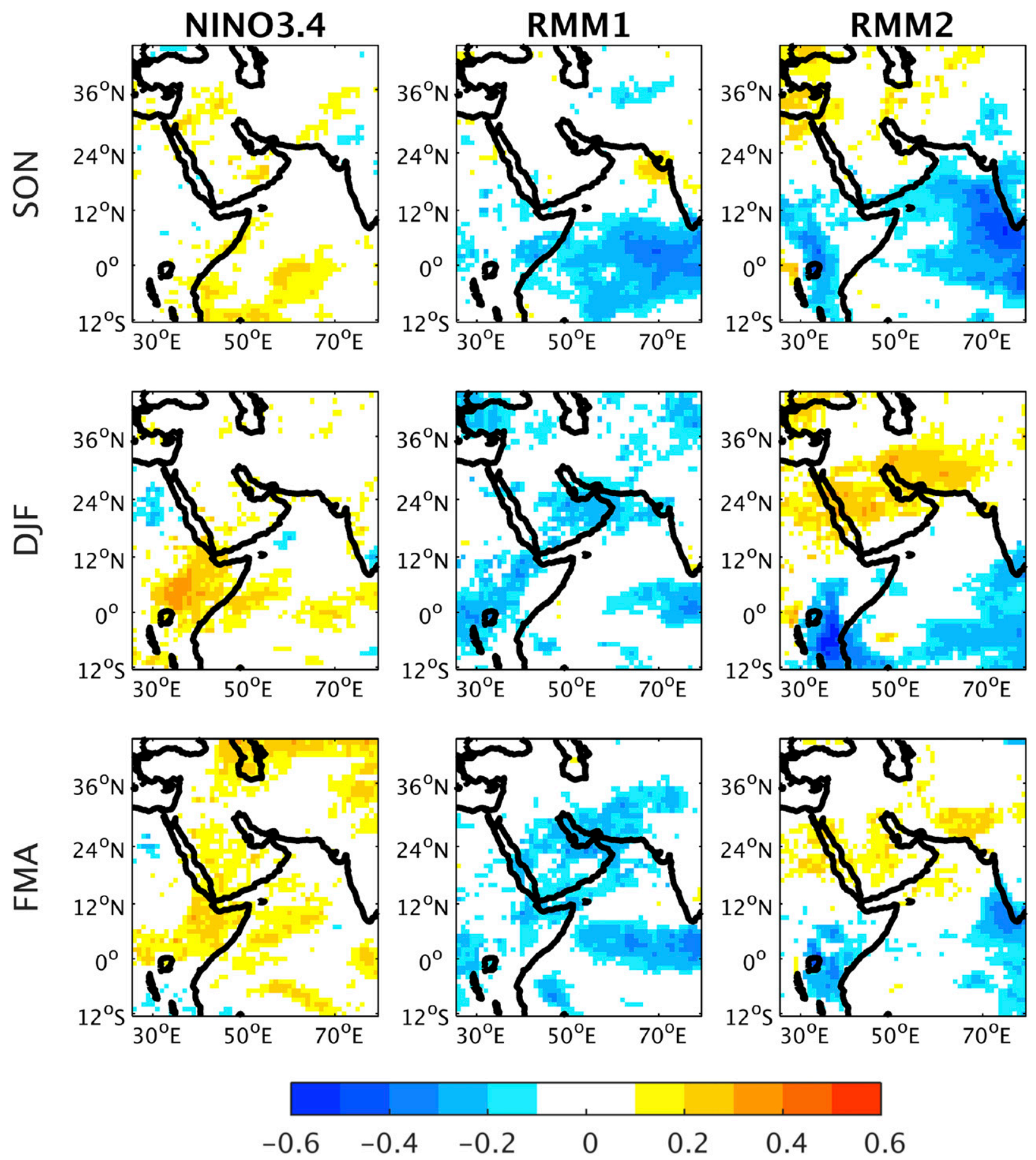

FIG. 10. Spatial correlation patterns of (left) GPCP weekly precipitation and observed weekly Niño-3.4 index and (center) MJO RMM1 and (right) RMM2 indices of Wheeler and Hendon (2004) in (top) SON, (middle) DJF, and (bottom) FMA. Only correlations significant at the 0.05 level using Monte Carlo simulations are plotted.

have significant climate impacts within the EA-WA sector; however, there are strong covariations between the IOD and ENSO associated with subsurface ocean variability. Since ENSO can modulate the IOD intensity and frequency (Wang et al. 2016) but also trigger the IOD (Yu and Lau 2005; Wang and Wang 2014), skill is not discretized on IOD phases in the following. In SON and FMA, skill is significantly enhanced in all subregions 

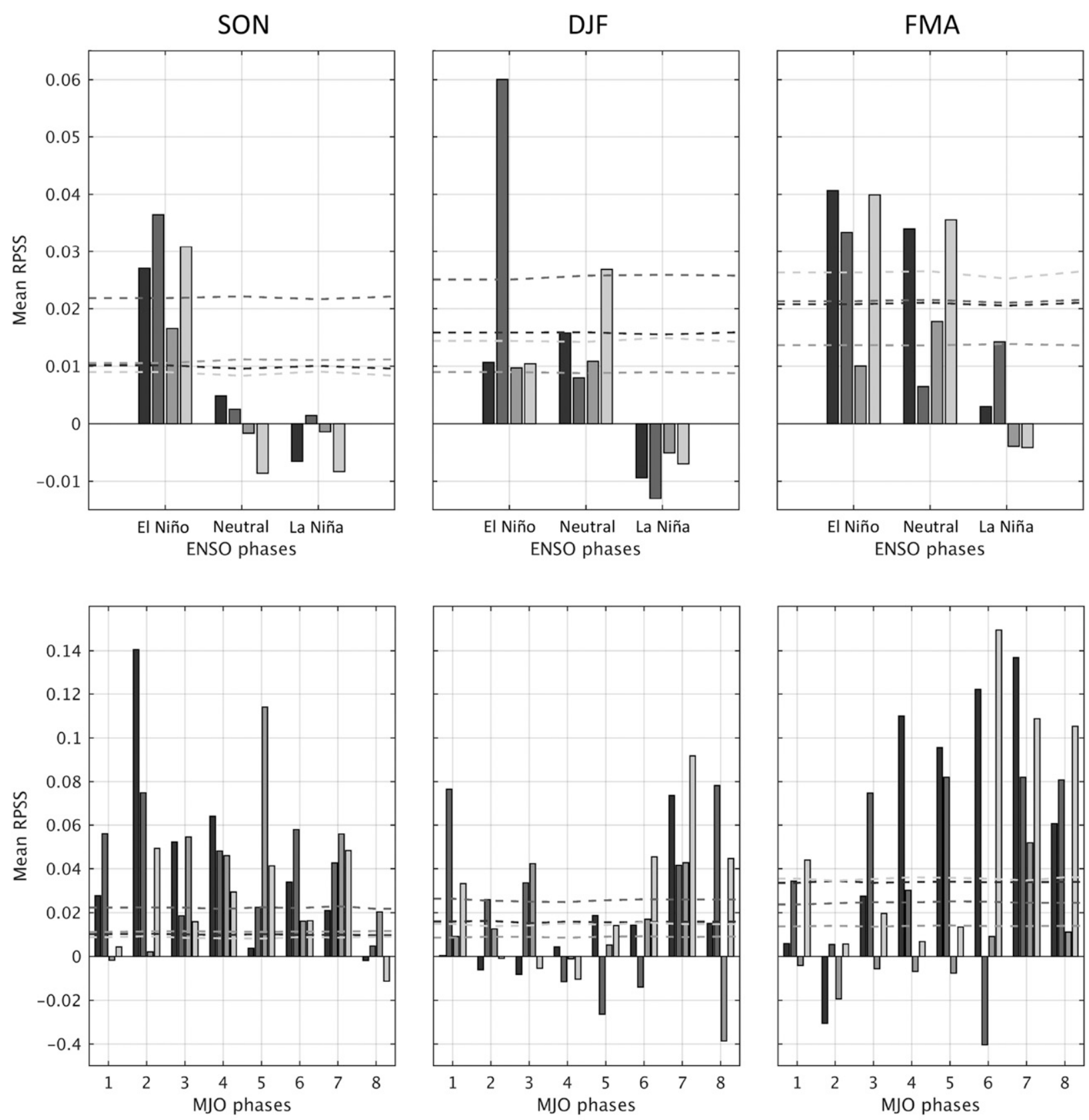

Arabian Peninsula $\square$ East Africa $\square$ Middle East $\square$ Persian regions

FIG. 11. Mean MME week-3-4 RPSSs averaged over the Arabian Peninsula, East Africa, the Middle East, and Persian regions for starts in (left) SON, (center) DJF, and (right) FMA during (top) observed phases of the Niño-3.4 index and (bottom) MJO phases measured by the RMM1 and RMM2 indices of Wheeler and Hendon (2004). Dashed lines correspond to a 0.1 level of significance using Monte Carlo simulations.

for starts during El Niño, except in DJF and over the Middle East in FMA, when maximum RPSS is found during neutral ENSO phases. Even though the small 11-yr 1999-2010 sample contains no strong El Niño events, these dependences are confirmed by positive correlations between mean RPSS and Niño-3.4 index results in Table 2. Figure 12 indicates that highest RPSS during El Niño generally coincides with enhanced forecasted probabilities for the above-normal category. Conversely, skill is lower on average during La Niña, when forecasts 
TABLE 2. Correlations between week-3-4 MME RPSSs averaged over the four continental regions (except East Africa in DJF in regard to the break between short and long rains) indicated in Fig. 2 and the observed Niño-3.4 index (second column), MJO measured by the RMM1 (third column), and RMM2 (fourth column) indices of Wheeler and Hendon (2004), and their best linear combination (fifth column). Scores in parentheses correspond to correlations with RPSS PC1 for each regions shown in Fig. 1, and those significant at the 0.1, 0.05, and 0.01 levels of significance using Monte Carlo simulations are indicated with *, **, and ***, respectively.

\begin{tabular}{|c|c|c|c|c|}
\hline & Niño-3.4 & RMM1 & RMM2 & MJO \\
\hline \multicolumn{5}{|l|}{ SON } \\
\hline Arabian Peninsula & $0.26 * * *\left(0.25^{* * *}\right)$ & $0.11(0.13)$ & $0.03(0.12)$ & $0.11\left(0.19^{* *}\right)$ \\
\hline East Africa & $0.26 * * *(0.30 * * *)$ & $-0.14 *(-0.10)$ & $0.07(0.08)$ & $0.16^{* *}(0.14 *)$ \\
\hline Middle East & $0.10(0.17 *)$ & $0.11(0.14 *)$ & $0.18 * *(0.20 * *)$ & $0.20 * *(0.24 * * *)$ \\
\hline Persian regions & $0.27 * * *(0.26 * * *)$ & $0.20 * *(0.19 * *)$ & $0.03(0.07)$ & $0.20 * *(0.20 * *)$ \\
\hline \multicolumn{5}{|l|}{ DJF } \\
\hline Arabian Peninsula & $0.20 * *(0.22 * *)$ & $-0.05(-0.04)$ & $0.12(0.13)$ & $0.12(0.14)$ \\
\hline Middle East & $0.19 * *(0.22 * *)$ & $0.04(0.03)$ & $0.07(0.06)$ & $0.09(0.07)$ \\
\hline Persian regions & $0.14^{*}\left(0.16^{*}\right)$ & $-0.08(0.14 *)$ & $0.16^{*}\left(0.16^{*}\right)$ & $0.18^{* *}(0.20 * *)$ \\
\hline \multicolumn{5}{|l|}{ FMA } \\
\hline Arabian Peninsula & $0.20 * *(0.16 *)$ & $0.04(0.03)$ & $0.27 * * *(0.24 * * *)$ & $0.27 * * *(0.24 * * *)$ \\
\hline East Africa & $0.21 * * *(0.27 * * *)$ & $0.02(0.05)$ & $-0.02(0.05)$ & $0.02(0.07)$ \\
\hline Middle East & $0.21 * * *(0.24 * * *)$ & $0.02(0.03)$ & $0.25 * * *(0.26 * * *)$ & $0.25^{* * *}\left(0.26^{* * *}\right)$ \\
\hline Persian regions & $0.23 * * *(0.23 * * *)$ & $-0.06(-0.07)$ & $0.27 * * *(0.26 * * *)$ & $0.27 * * *(0.27 * * *)$ \\
\hline
\end{tabular}

tend to be for drier than normal conditions. Because we aimed at producing comparable sets of forecasts across models, the robustness of such results was not tested for the longer ECMWF and CMA reforecast periods; however, this aspect could be further investigated, in particular, regarding skill relationships to ENSO. In SON, these could be explained by El Niño relationships to increased East African short rains (Beltrando 1990; Beltrando and Camberlin 1993; Goddard and Graham 1999; Indeje et al. 2000; Nicholson 2015) and boreal winter rainfall over the Arabian Peninsula (Kang et al. 2015), the Middle East, and Persian regions (Hoell et al. 2013). Maximum RPSS during neutral ENSO phases over the latter three regions in DJF and the Middle East in FMA could be evidence of increased modulations of ENSO relationships by the IO (Hoell et al. 2014) as the winter season unfolds, while the highest values for El Niño over East Africa in FMA could reflect the long rains relationships with the west-central Pacific SST gradient (Lyon and DeWitt 2012; Liebmann et al. 2014; Vigaud et al. 2016).

Mean RPSS also varies with MJO phases (Fig. 11, bottom) in agreement with regional MJO relationships (Hoell et al. 2013). The highest RPSS is found across most subregions around MJO phase 7, when convection is enhanced over the western Pacific and RMM1 and RMM2 are, respectively, negative and positive. This behavior is consistent with mean RPSS anticorrelations to RMM1 for East Africa in SON, positive correlation to RMM2 for Persian regions in DJF, and for the Arabian Peninsula, Middle East, and Persian regions in FMA (Table 2). In DJF and FMA, Fig. 12 displays systematically higher forecasted probabilities for the above-normal category during MJO phase 7 everywhere. Overall, the highest mean RPSS and probability ranges across MJO phases compared to ENSO suggest stronger MJO modulations of skill and subsequent probabilistic forecasts. For SON starts, however, RPSS values over the Arabian Peninsula, East Africa, and Persian regions are maximum during MJO phase 2 and over the Middle East during phase 5, when convection is enhanced over the IO and the Maritime Continent (MC), respectively. In MJO phase 2, RMM1 is negative and the highest skill over East Africa in SON is consistent with mean RPSS anticorrelations to RMM1 (Table 2), while Fig. 12 indicates barely significant above-normal probabilities. Highest RPSSs for MJO phases 2 and 7 over the Arabian Peninsula corroborate MJO relationships identified in probabilistic forecasts (Tippett et al. 2015) and increased precipitation for negative values of RMM1 (Barlow et al. 2005). Higher skill with enhanced above-normal probabilities over Persian regions in DJF and FMA could reflect more frequent tropical moisture plumes during phases 5-8 (Rubin et al. 2007; Lau et al. 2012). Maximum RPSS over East Africa in FMA agrees with reduced long rains during MJO phase 5 (Berhane et al. 2015), when RMM2 is positive, consistent with Table 2.

A principal component analysis (PCA) is applied to week-3-4 MME RPSS values (total values; the mean is not removed) over land points of each subregion at weekly resolution to examine if the regional structure of skill can be decomposed in geographically coherent patterns of variability. Spatial correlations typical of the first principal components (PCs) are plotted in Fig. 13 for each region, where they account for a substantial part of the total variance explained $(20 \%-40 \%)$ and are 

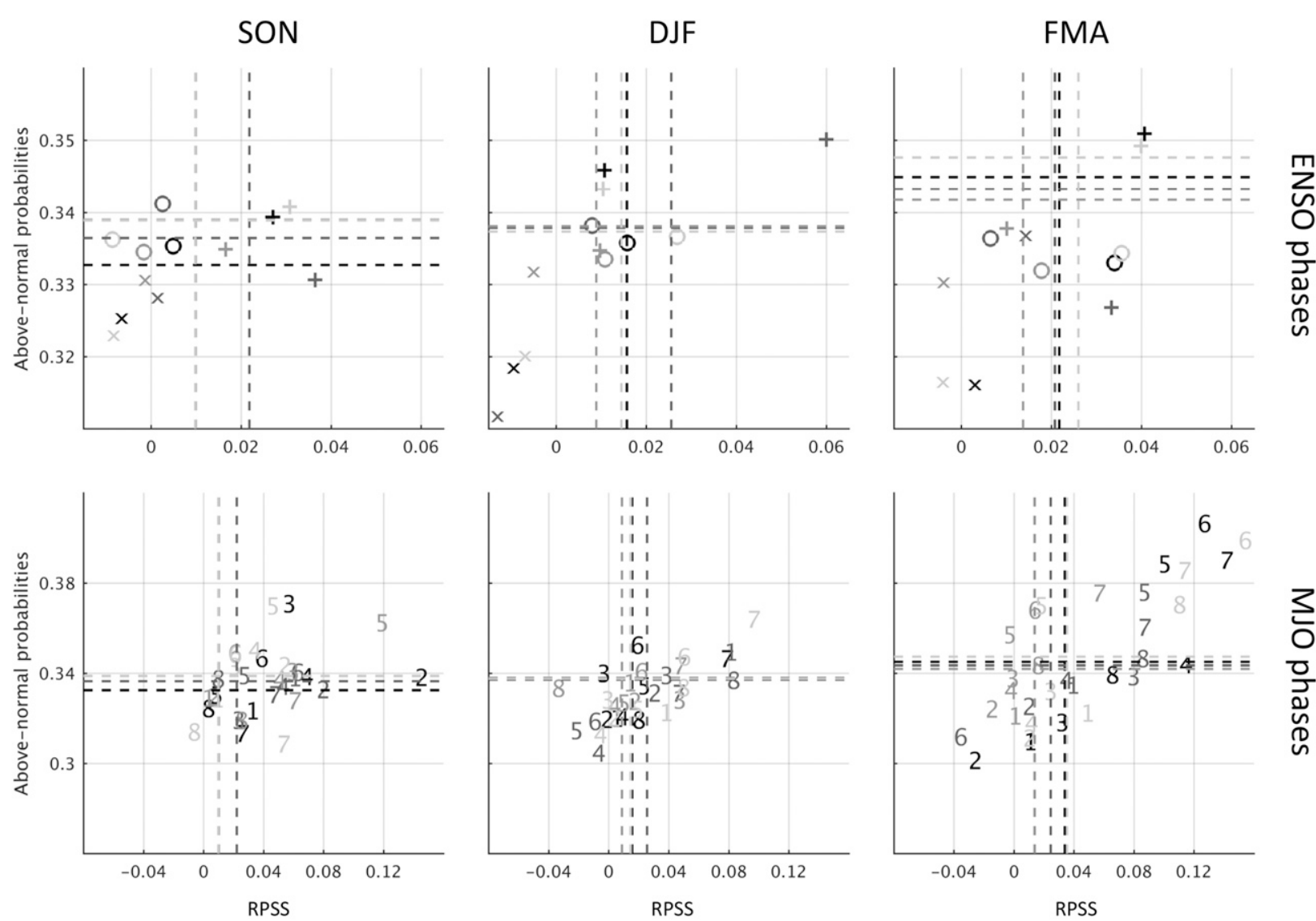

FIG. 12. Mean week-3-4 RPSS vs above-normal probabilities averaged over the Arabian Peninsula, East Africa, the Middle East, and Persian regions for starts in (left) SON, (center) DJF, and (right) FMA during observed (top) ENSO and (bottom) MJO phases. El Niño, neutral ENSO, and La Niña phases are indicated by plus signs (+), open circles (o), and exes (x), respectively, and those of the MJO by their respective number. Dashed lines correspond to a 0.1 level of significance using Monte Carlo simulations.

highly correlated to the mean RPSS (between 0.72 and 0.99). Over the Arabian Peninsula, maximum PC1 loadings from the Red Sea coast across to the Oman Sea coastline coincide with some of the positive correlations between weekly rainfall and Niño-3.4, but most similarities are found with RMM2 correlations in DJF and FMA (Fig. 10), agreeing with Table 2. East African rainfall correlations to Niño-3.4 in SON are not significant (Fig. 10), which might reflect the small sample of events across the short period of study and IO modulations of ENSO teleconnections during the short rains (Hoell et al. 2014). However, PC1 loadings resemble those of weekly rainfall anticorrelations to RMM1 in agreement with the mean RPSS (Table 2). ENSO relationships in Fig. 10 are more significant in FMA and match parts of the PC1 loadings consistently with Table 2, also corroborating similarities between PC1 patterns and Niño-3.4 correlations in FMA over the Middle East and in SON over Persian regions, where PC1 coincides with RMM2 correlations in DJF and FMA.

\section{Conclusions}

The skill from S2S precipitation forecasts using ECMWF, NCEP, and CMA week-1-4 leads has been examined, over the 1999-2010 common hindcast period for the East Africa-West Asia sector (Fig. 1), including the Arabian Peninsula, East Africa, the Middle East, and Persian subregions, where probabilistic tercile category forecasts are constructed using extended logistic regression (ELR). For each start and lead, terciles are defined with a 3-week window centered on the target week and the same pool of weeks is used to train the ELR model out of sample. Forecasts are only produced where and when the lower tercile is nonzero to accommodate the discontinuity between zero rain and rainy events in the observed precipitation distribution. Resulting 

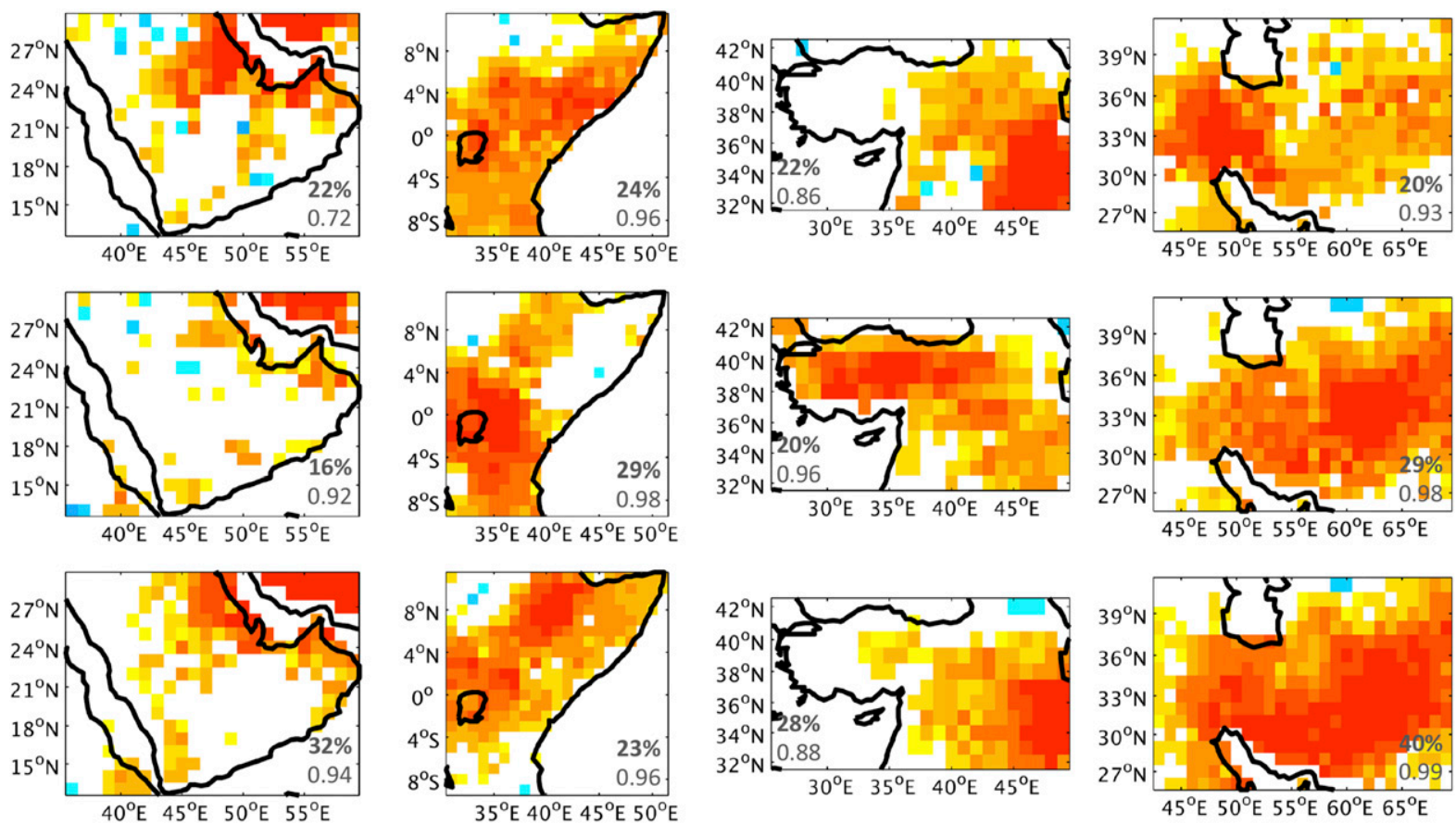

FIG. 13. Spatial correlation patterns of week-3-4 MME leading RPSS PC1 for starts in (top) SON, (middle) DJF, and (bottom) FMA. Only correlations significant at the 0.05 level using Monte Carlo simulations are plotted. The fraction of total variance explained by each PC is indicated in the different panels (\%) as well as their correlations to spatially averaged RPSSs.

weekly precipitation tercile forecasts have reasonable skill at week-1 lead as shown by the high RPSS values in Figs. 2-4, as well as good reliability, resolution, and sharpness in Fig. 5. Skill sharply drops after weeks 1 and 2 for individual models as well as their MMEs everywhere, while skill is low for longer leads when forecasts are characterized by low sharpness (Figs. 2-5).

Week-3 and -4 leads are next combined together as an attempt to improve the skill and produce week-3-4 precipitation tercile probabilities (Fig. 6). Biweekly terciles are defined using data from 6-week windows centered on the week-3-4 targets. The model is trained for each start separately and then applied to out-ofsample data. The skill of the week-3-4 averages is enhanced from week -3 and -4 forecasts in terms of RPSS and reliability for starts in February-April but the skill gain is less pronounced in other seasons, and sharpness still remains low (Figs. 7-9).

Observed weekly rainfall correlations to Niño-3.4 and MJO RMM indices (Fig. 10) suggest skill relationships to both large-scale signals and these are examined by averaging RPSSs, as well as forecasted probabilities, over land grid points of each subregion (Table 2 and Figs. 11 and 12), where a PCA is separately applied to week-3-4 MME RPSSs (Fig. 13). The part of the total variance explained by each $\mathrm{PC} 1$ is reasonable, with significant correlations to spatially averaged RPSSs indicating that PC1 represents the spatially coherent component of the RPSS variability in each region. The patterns associated with the first PCs bear some similarities to correlations between weekly GPCP rainfall and the Niño-3.4 index across most subregions (Fig. 10), where the skill is greater for starts during El Niño compared to La Niña and neutral conditions (Fig. 11) and coincides with maximum forecasted probabilities of the above-normal category (Fig. 12). Despite the small sample of ENSO episodes during the 11-yr period, the asymmetry between both phases could be explained by El Niño relationships to increased East African short rains (Beltrando 1990; Beltrando and Camberlin 1993; Goddard and Graham 1999; Indeje et al. 2000; Nicholson 2015) and boreal winter rainfall over the Arabian Peninsula (Kang et al. 2015), Middle East, and Persian regions (Hoell et al. 2013). The highest skill for neutral ENSO phases over the latter three regions from DJF to FMA and for El Niño over East Africa in FMA could, respectively, reflect increased modulations of ENSO teleconnections by the IO (Hoell et al. 2014) and the 
long rains relationships to the west-central Pacific SST gradient (Lyon and DeWitt 2012; Vigaud et al. 2016).

The highest skill in MJO phase 7 (Fig. 11), when convection is enhanced over the western Pacific, coincides with maximum above-normal probabilities (Fig. 12) that are more substantially modulated by the MJO compared to ENSO, and agrees with RPSS relationships to RMM indices (Table 2 and Fig. 13). Maximum RPSSs over the Arabian Peninsula, East Africa and Persian regions in SON during MJO phase 2, when convection is enhanced over the IO, corroborate the local MJO relationships (Barlow et al. 2005; Tippett et al. 2015). The highest skill and above-normal probabilities over Persian regions in DJF/FMA and over East Africa in FMA could be explained by more frequent tropical moisture plumes during phases 5-8 (Rubin et al. 2007; Lau et al. 2012) and reduced long rains during phase 5 (Berhane et al. 2015). Overall, these results suggest opportunities for application of skillful predictions in the EA-WA sector especially during El Niño and specific MJO phases.

Acknowledgments. The authors are grateful to the reviewers, whose suggestions helped improve the manuscript substantially. The authors also acknowledge the financial support of the NOAA Next Generation Global Prediction System (NGGPS; Grant NA15NWS4680014) and the use of forecasts available through the S2S database published under the WWRP/WCRP S2S project (http://s2sprediction.net). Calculations were performed using the S2S subset archived on the IRI Data Library (IRIDL; http://iridl.ldeo.columbia.edu/). The IRIDL was also used to access GPCP 1DD data from the NASA Goddard Space Flight Center's Mesoscale Atmospheric Processes Laboratory, which computes the 1DD as a contribution to the GEWEX Global Precipitation Climatology Project.

\section{REFERENCES}

Abdullah, M., and M. Al-Mazroui, 1998: Climatological study of the southwestern region of Saudi Arabia. I. Rainfall analysis. Climate Res., 9, 213-223, https://doi.org/10.3354/cr009213.

Baldwin, M., and T. Dunkerton, 2001: Stratospheric harbingers of anomalous weather regimes. Science, 294, 581-584, https:// doi.org/10.1126/science.1063315.

Barlow, M., H. Cullen, and B. Lyon, 2002: Drought in central and southwest Asia: La Niña, the warm pool, and Indian Ocean precipitation. J. Climate, 15, 697-700, https://doi.org/10.1175/ 1520-0442(2002)015<0697:DICASA > 2.0.CO;2.

- M. Wheeler, B. Lyon, and H. Cullen, 2005: Modulation of daily precipitation over southwest Asia by the Madden-Julian oscillation. Mon. Wea. Rev., 133, 3579-3594, https://doi.org/ 10.1175/MWR3026.1.

Barnston, A., and M. Tippett, 2014: Climate information, outlooks, and understanding - Where does the IRI stand? Earth Perspect., 1 (20), https://doi.org/10.1186/2194-6434-1-20.
_ M. Chelliah, and S. Goldenberg, 1997: Documentation of a highly ENSO-related SST region in the equatorial Pacific: Research note. Atmos.-Ocean, 35, 367-383, https://doi.org/ 10.1080/07055900.1997.9649597.

Behera, S., J. Luo, S. Mason, P. Delecluse, S. Gualdi, A. Navarra, and T. Yamagata, 2005: Paramount impact of the Indian Ocean dipole on the East African short rains: A CGCM study. J. Climate, 18, 4514-4530, https://doi.org/10.1175/JCLI3541.1.

Beltrando, G., 1990: Space-time variability of rainfall in April and October-November over East Africa during the period 19321983. Int. J. Climatol., 10, 691-702, https://doi.org/10.1002/ joc. 3370100704 .

_ , and P. Camberlin, 1993: Interannual variability of rainfall in the eastern Horn of Africa and indicators of atmospheric circulation. Int. J. Climatol., 13, 533-546, https://doi.org/ 10.1002/joc.3370130505.

Berhane, F., B. Zaitchik, and H. Badr, 2015: The Madden-Julian oscillation influence on spring rainy season precipitation over equatorial West Africa. J. Climate, 28, 8653-8672, https:// doi.org/10.1175/JCLI-D-14-00510.1.

Charabi, Y., and S. A. Abdul-Wahab, 2009: Synoptic aspects of the summer monsoon of southern Oman and its global teleconnections. J. Geophys. Res., 114, D07107, https://doi.org/ 10.1029/2008JD010234.

Daan, H., 1985: Sensitivity of verification scores to the classification of the predictand. Mon. Wea. Rev., 113, 1384-1392, https:// doi.org/10.1175/1520-0493(1985)113<1384:SOVSTT>2.0.CO;2.

DelSole, T., L. Trenary, M. Tippett, and K. Pegion, 2017: Predictability of week-3-4 average temperature and precipitation over the contiguous United States. J. Climate, 30, 3499-3512, https://doi.org/10.1175/JCLI-D-16-0567.1.

de Vries, A. J., E. Tyrlis, D. Edry, S. Krichak, B. Steil, and J. Lelieveld, 2013: Extreme precipitation events in the Middle East: Dynamics of the active Red Sea trough. J. Geophys. Res. Atmos., 118, 7087-7108, https://doi.org/10.1002/jgrd.50569.

- H. G. Ouwersloot, S. Feldstein, M. Riemer, A. E. Kenawy, M. McCabe, and J. Lelieveld, 2018: Identification of tropicalextratropical interactions and extreme precipitation events in the Middle East based on potential vorticity and moisture transport. J. Geophys. Res. Atmos., 123, 861-881, https:// doi.org/10.1002/2017JD027587.

Epstein, E., 1969: A scoring system for probability forecasts of ranked categories. J. Appl. Meteor., 8, 985-987, https://doi.org/ 10.1175/1520-0450(1969)008<0985:ASSFPF > 2.0.CO;2.

Feudale, L., and F. Kucharski, 2013: A common mode of variability of African and Indian monsoon rainfall. Climate Dyn., 41, 243-254, https://doi.org/10.1007/s00382-013-1827-4.

Gill, A., 1980: Some simple solutions for heat-induced tropical circulation. Quart. J. Roy. Meteor. Soc., 106, 447-462, https:// doi.org/10.1002/qj.49710644905.

Goddard, L., and N. Graham, 1999: The importance of the Indian Ocean for simulating precipitation anomalies over eastern and southern Africa. J. Geophys. Res., 104, 19 099-19116, https:// doi.org/10.1029/1999JD900326.

— S. Mason, S. Zebiak, C. Ropelewski, R. Basher, and M. Cane, 2001: Current approaches to seasonal to interannual climate predictions. Int. J. Climatol., 21, 1111-1152, https://doi.org/ 10.1002/joc.636.

Hamill, T., 1997: Reliability diagrams for multicategory probabilistic forecasts. Wea. Forecasting, 12, 736-741, https://doi.org/ 10.1175/1520-0434(1997)012<0736:RDFMPF >2.0.CO;2.

, and J. Whitaker, 2006: Probabilistic quantitative precipitation forecasts based on reforecast analogs: Theory and 
application. Mon. Wea. Rev., 134, 3209-3229, https://doi.org/ 10.1175/MWR3237.1.

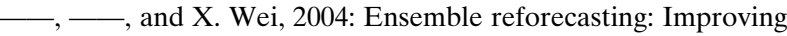
medium-range forecast skill using retrospective forecasts. Mon. Wea. Rev., 132, 1434-1447, https://doi.org/10.1175/15200493(2004)132<1434:ERIMFS > 2.0.CO;2.

Hastenrath, S., A. Niklis, and L. Greischar, 1993: Atmospherichydrospheric mechanisms of climate anomalies in the western equatorial Indian Ocean. J. Geophys. Res., 98, 20 219-20 235, https://doi.org/10.1029/93JC02330.

Hoell, A., M. Barlow, and R. Sani, 2013: Intraseasonal and seasonal-to-interannual Indian Ocean convection and hemispheric teleconnections. J. Climate, 26, 8850-8867, https:// doi.org/10.1175/JCLI-D-12-00306.1.

_ , C. Funk, and M. Barlow, 2014: La Niña diversity and northwest Indian Ocean rim teleconnections. Climate Dyn., 43, 2707-2714, https://doi.org/10.1007/s00382-014-2083-y.

Holland, M. M., D. A. Bailey, and S. Vavrus, 2011: Inherent sea ice predictability in the rapidly changing Arctic environment of the Community Climate System Model version 3. Climate Dyn., 36, 1239-1253, https://doi.org/10.1007/s00382-010-0792-4.

Huffman, G., and D. Bolvin, 2012: Version 1.2 GPCP One-Degree Daily (1DD) precipitation dataset documentation. NCDC, 27 pp., ftp://meso.gsfc.nasa.gov/pub/1dd-v1.2/1DD_v1.2_doc.pdf.

_ , R. Adler, M. Morrissey, D. Bolvin, S. Curtis, R. Joyce, B. McGavock, and J. Susskind, 2001: Global precipitation at one-degree daily resolution from multisatellite observations. J. Hydrometeor., 2, 36-50, https://doi.org/10.1175/1525-7541 (2001)002<0036:GPAODD>2.0.CO;2.

Indeje, M., F. Semazzi, and L. Ogallo, 2000: ENSO signals in East African rainfall seasons. Int. J. Climatol., 20, 19-46, https://doi.org/10.1002/(SICI)1097-0088(200001)20:1<19::AIDJOC449>3.0.CO;2-0.

Jones, C., D. Waliser, K. Lau, and W. Stern, 2004: Global occurrences of extreme precipitation and the Madden-Julian oscillation: Observations and predictability. J. Climate, 17, 4575-4589, https://doi.org/10.1175/3238.1.

Kang, I.-S., I. Rashid, F. Kucharski, M. Almazroui, and A. A. Khalaf, 2015: Multidecadal changes in the relationship between ENSO and wet-season precipitation in the Arabian Peninsula. J. Climate, 28, 4743-4752, https://doi.org/10.1175/ JCLI-D-14-00388.1.

Kijazi, A., and C. Reason, 2005: Relationships between intraseasonal rainfall variability of coastal Tanzania and ENSO. Theor. Appl. Meteor., 82, 153-176, https://doi.org/10.1007/ s00704-005-0129-0.

Koster, R., and Coauthors, 2010: Contribution of land surface initialization to subseasonal forecast skill: First results from a multi-model experiment. Geophys. Res. Lett., 37, L02402, https://doi.org/10.1029/2009GL041677.

Kumar, P., M. R. K. Rupa Kumar, and A. Sahai, 2007: On the recent strengthening of the relationship between ENSO and northeast monsoon rainfall over South Asia. Climate Dyn., 28, 649-660, https://doi.org/10.1007/s00382-006-0210-0.

Lau, W., D. Waliser, and M. Barlow, 2012: Africa and West Asia. Intraseasonal Variability in the Atmosphere-Ocean Climate System, W. K.-M. Lau and D. E. Waliser, Eds., Springer Praxis, 1-19, https://doi.org/10.1007/978-3-642-13914-7.

Liebmann, B., and Coauthors, 2014: Understanding the eastern Horn of Africa rainfall variability and change. J. Climate, 27, 8630-8645, https://doi.org/10.1175/JCLI-D-13-00714.1.

Lin, H., and Z. Wu, 2011: Contribution of the autumn Tibetan Plateau snow cover to seasonal prediction of North American winter temperature. J. Climate, 24, 2801-2813, https://doi.org/ 10.1175/2010JCLI3889.1.

Lyon, B., and D. DeWitt, 2012: A recent and abrupt decline in the East African long rains. Geophys. Res. Lett., 39, L02702, https://doi.org/10.1029/2011GL050337.

Mani, N. J., J. Y. Lee, D. Waliser, B. Wang, and X. Jiang, 2014: Predictability of the Madden-Julian oscillation in the Intraseasonal Variability Hindcast Experiment (ISVHE). J. Climate, 27, 4531-4543, https://doi.org/10.1175/JCLI-D-13-00624.1.

Mason, S., 1995: Sea-surface temperatures-South African rainfall associations, 1910-1989. Int. J. Climatol., 15, 119-135, https:// doi.org/10.1002/joc.3370150202.

Matsuno, T., 1966: Quasi-geostrophic motions in the equatorial area. J. Meteor. Soc. Japan, 44, 25-43, https://doi.org/10.2151/ jmsj1965.44.1_25.

Moron, V., R. Bombardi, H. Hendon, A. Marshall, A. Kumar, and R. Chattopadhyay, 2018: Monsoon sub-seasonal prediction. Sixth Int. Workshop on Monsoons, Singapore, WMO, 140-146, https://www.wmo.int/pages/prog/arep/wwrp/new/documents/ IWM6AbstractsVolume.pdf.

Murphy, A., 1969: On the ranked probability skill score. J. Appl. Meteor., 8, 988-989, https://doi.org/10.1175/1520-0450(1969) 008<0988:OTPS $>2.0$. CO;2.

_ 1971: A note on the ranked probability skill score. J. Appl. Meteor., 10, 155-156, https://doi.org/10.1175/1520-0450(1971) $010<0155$ :ANOTRP $>2.0 . C O ; 2$.

Mutai, C., and M. Ward, 2000: East African rainfall and the tropical circulation/convection on intraseasonal to interannual timescales. J. Climate, 13, 3915-3939, https://doi.org/10.1175/15200442(2000)013<3915:EARATT>2.0.CO;2.

Nazemosadat, M., and H. Ghaedamini, 2010: On the relationships between the Madden-Julian oscillation and precipitation variability in southern Iran and the Arabian Peninsula: Atmospheric circulation analysis. J. Climate, 23, 887-904, https:// doi.org/10.1175/2009JCLI2141.1.

Nicholson, S. E., 2015: An analysis of recent rainfall conditions in eastern Africa. Int. J. Climatol., 36, 526-532, https://doi.org/ 10.1002/joc. 4358 .

Ogallo, L., 1988: Relationships between seasonal rainfall in East Africa and the Southern Oscillation. J. Climatol., 8, 31-43, https://doi.org/10.1002/joc.3370080104.

_- J. Janowiak, and M. Halpert, 1988: Teleconnections between seasonal rainfall over East Africa and global sea surface temperature anomalies. J. Meteor. Soc. Japan, 66, 807-822, https://doi.org/10.2151/jmsj1965.66.6_807.

Ogutu, G. E., W. Franssen, I. Supit, P. Omondi, and R. Hutjes, 2017: Skill of ECMWF system-4 ensemble seasonal climate forecasts for East Africa. Int. J. Climatol., 37, 2734-2756, https://doi.org/10.1002/joc.4876.

Phillips, A., and B. McIntyre, 2000: ENSO and interannual variability in Uganda: Implications for agricultural management. Int. J. Climatol., 20, 171-182, https://doi.org/10.1002/(SICI)10970088(200002)20:2<171::AID-JOC471>3.0.CO;2-O.

Pohl, B., and P. Camberlin, 2006a: Influence of the Madden-Julian oscillation on East African rainfall. I: Intraseasonal variability and regional dependency. Quart. J. Roy. Meteor. Soc., 132, 2421-2539, https://doi.org/10.1256/qj.05.104.

, and - 2006b: Influence of the Madden-Julian oscillation on East African rainfall. II: March-May season extremes and interannual variability. Quart. J. Roy. Meteor. Soc., 132, 25412558, https://doi.org/10.1256/qj.05.223.

Robertson, A., U. Lall, S. E. Zebiak, and L. Goddard, 2004: Improved combination of multiple atmospheric GCM ensembles 
for seasonal prediction. Mon. Wea. Rev., 132, 2732-2744, https://doi.org/10.1175/MWR2818.1.

Rubin, S., B. Ziv, and N. Paldor, 2007: Tropical plumes over eastern North Africa as a source of rain in the Middle East. Mon. Wea. Rev., 135, 4135-4148, https://doi.org/10.1175/ 2007MWR1919.1.

Saji, N., B. Goswami, P. Vinayachandran, and T. Yamagata, 1999: A dipole mode in the tropical Indian Ocean. Nature, 401, 360363, https://doi.org/10.1038/43854.

Scaife, A., and J. Knight, 2008: Ensemble simulations of the cold European winter of 2005/6. Quart. J. Roy. Meteor. Soc., 134, 1647-1659, https://doi.org/10.1002/qj.312.

Shaman, J., and E. Tziperman, 2005: The effect of ENSO on Tibetan Plateau snow depth: A stationary wave teleconnection mechanism and implications for the south Asian monsoons. J. Climate, 18, 2067-2079, https://doi.org/10.1175/JCLI3391.1.

Tippett, M., A. Barnston, and A. Robertson, 2007: Estimation of seasonal precipitation tercile-based categorical probabilities from ensembles. J. Climate, 20, 2210-2228, https://doi.org/ 10.1175/JCLI4108.1.

$\longrightarrow, \ldots$, and T. DelSole, 2010: Comments on "Finite samples and uncertainty estimates for skill measures for seasonal prediction." Mon. Wea. Rev., 138, 1487-1493, https://doi.org/ 10.1175/2009MWR3214.1.

_-, M. Almazroui, and I.-S. Kang, 2015: Extended-range forecasts of areal-averaged rainfall over Saudi Arabia. Wea. Forecasting, 30, 1090-1105, https://doi.org/10.1175/WAF-D15-0011.1.

Trenberth, K., G. Branstator, D. Karoly, A. Kumar, N.-C. Lau, and C. Ropelewski, 1998: Progress during TOGA in understanding and modeling global teleconnections associated with tropical sea surface temperatures. J. Geophys. Res., 103, 14 291-14324, https://doi.org/10.1029/97JC01444.

Vigaud, N., B. Lyon, and A. Giannini, 2016: Sub-seasonal teleconnections between convection over the Indian Ocean, the East African long rains and tropical Pacific surface temperatures. Int. J. Climatol., 3, 1167-1180, https://doi.org/10.1002/ joc. 4765 .

— A. Robertson, and M. Tippett, 2017a: Multimodel ensembling of subseasonal precipitation forecasts over North America. Mon. Wea. Rev., 145, 3913-3928, https://doi.org/ 10.1175/MWR-D-17-0092.1.

$\longrightarrow,-,-$, and N. Acharya, 2017b: Subseasonal predictability of boreal summer monsoon rainfall from ensemble forecasts. Front. Environ. Sci., 5, 67, https://doi.org/10.3389/ fenvs.2017.00067.

Vitart, F., 2014: Evolution of ECMWF sub-seasonal forecast skill scores. Quart. J. Roy. Meteor. Soc., 140, 1889-1899, https:// doi.org/10.1002/qj.2256.

— Prediction Project database. Bull. Amer. Meteor. Soc., 98, 163-173, https://doi.org/10.1175/BAMS-D-16-0017.1.

Waliser, D., 2011: Predictability and forecasting. Intraseasonal Variability of the Atmosphere-Ocean Climate System,
W. K.-M. Lau and D. E. Waliser, Eds., Springer Praxis, 389-423, https://doi.org/10.1007/3-540-27250-X_12.

_ dictability of the Madden-Julian oscillation. Bull. Amer. Meteor. Soc., 84, 33-50, https://doi.org/10.1175/BAMS-84-1-33.

Walker, N., 1990: Links between South African summer rainfall and temperature variability of the Agulhas and Benguela current systems. J. Geophys. Res., 95, 3297-3319, https:// doi.org/10.1029/JC095iC03p03297.

Wang, H., R. Murtugudde, and A. Kumar, 2016: Evolution of Indian Ocean dipole and its forcing mechanisms in the absence of ENSO. Climate Dyn., 47, 2481-2500, https://doi.org/ 10.1007/s00382-016-2977-y.

Wang, X., and C. Wang, 2014: Different impacts of various El Niño events on the Indian Ocean dipole. Climate Dyn., 42, 9911005, https://doi.org/10.1007/s00382-013-1711-2.

Weigel, A., M. Liniger, and C. Appenzeller, 2007: The discrete Brier and ranked probability skill scores. Mon. Wea. Rev., 135, 118-124, https://doi.org/10.1175/MWR3280.1.

Wheeler, M., and H. Hendon, 2004: An all-season real-time multivariate MJO index: Development of an index for monitoring and prediction. Mon. Wea. Rev., 132, 1917-1932, https://doi.org/10.1175/1520-0493(2004)132<1917:AARMMI> 2.0.CO;2.

Wilks, D., 1995: Statistical Methods in the Atmospheric Sciences: An Introduction. Academic Press, $467 \mathrm{pp}$.

_ 2002: Smoothing forecast ensembles with fitted probability distributions. Quart. J. Roy. Meteor. Soc., 128, 2821-2836, https://doi.org/10.1256/qj.01.215.

- 2009: Extending logistic regression to provide fullprobability-distribution MOS forecasts. Meteor. Appl., 16, 361-368, https://doi.org/10.1002/met.134.

— , and T. Hamill, 2007: Comparison of ensemble MOS methods using GFS reforecasts. Mon. Wea. Rev., 135, 2379-2390, https://doi.org/10.1175/MWR3402.1.

World Meteorological Organization, 2013: Subseasonal to Seasonal Prediction: Research Implementation Plan. WMO Rep., 71 pp., https://library.wmo.int/pmb_ged/subseasonal_to_ seasonal_prediction-research_implementation_plan_2012.pdf.

Yadav, R., J. Yoo, F. Kucharski, and M. Abid, 2010: Why is ENSO influencing northwest India winter precipitation in recent decades? J. Climate, 23, 1979-1993, https://doi.org/10.1175/ 2009JCLI3202.1.

Yu, J.-Y., and K. Lau, 2005: Contrasting Indian Ocean SST variability with and without ENSO influence: A coupled atmosphere-ocean GCM study. Meteor. Atmos. Phys., 90, 179-191, https://doi.org/10.1007/s00703-004-0094-7.

Zhang, C., 2013: Madden-Julian oscillation: Bridging weather and climate. Bull. Amer. Meteor. Soc., 94, 1849-1870, https:// doi.org/10.1175/BAMS-D-12-00026.1.

Zhu, H., M. Wheeler, A. Sobel, and D. Hudson, 2014: Seamless precipitation prediction skill in the tropics and extratropics from a global model. Mon. Wea. Rev., 142, 1556-1569, https:// doi.org/10.1175/MWR-D-13-00222.1. 